\title{
A systematic review and meta-analysis on the treatment of liver hydatid cyst using meta-MUMS tool: comparing PAIR and laparoscopic procedures
}

\author{
Massoud Sokouti ${ }^{1}$, Ramin Sadeghi ${ }^{1}$, Saeid Pashazadeh ${ }^{2}$, Saeed Eslami Hasan Abadi ${ }^{3}$, \\ Mohsen Sokouti ${ }^{4}$, Morteza Ghojazadeh ${ }^{5}$, Babak Sokouti ${ }^{6}$
}

\author{
${ }^{1}$ Nuclear Medicine Research Center, Mashhad University of Medical Sciences, \\ Mashhad, Iran \\ ${ }^{2}$ Department of Computer and Electrical Engineering, University of Tabriz, Tabriz, Iran \\ ${ }^{3}$ Department of Medical Informatics, Faculty of Medicine, Mashhad University \\ of Medical Sciences, Mashhad, Iran \\ ${ }^{4}$ Department of Cardiothoracic Surgery, Tabriz University of Medical Sciences, Tabriz, Iran \\ ${ }^{5}$ Research Center for Evidence-Based Medicine, Tabriz University of Medical Sciences, \\ Tabriz, Iran \\ ${ }^{6}$ Biotechnology Research Center, Tabriz University of Medical Sciences, Tabriz, Iran
}

Submitted: 31 October 2016

Accepted: 20 March 2017

Arch Med Sci 2019; 15, 2: 284-308

DOI: https://doi.org/10.5114/aoms.2018.73344

Copyright @ 2018 Termedia \& Banach

\section{Abstract}

Introduction: There is an academic debate over surgical treatments of liver hydatid cyst disease. In this study, a systematic review and meta-analysis were carried out in order to evaluate the pros and cons of both PAIR (Puncture, Aspiration, Injection, Respiration) and laparoscopic techniques by considering the outcomes of liver hydatid cysts.

Material and methods: We designed descriptive Boolean queries to search two databases, PubMed and Scopus, to derive the articles published in the period of January 2000 to December 2016 in order to evaluate the outcomes of these research articles. The outcomes of laparoscopic and PAIR procedures include the rates of cure, postoperative complications, recurrences, and mortality, which were extracted, assessed, and used as their corresponding effect sizes.

Results: Fifty-seven studies including a total of 2832 patients (PAIR group $n=1650$ and laparoscopic group $=1182$ ) were analyzed. In this meta-analysis study, a random effect model of correlations of outcomes (postoperative complications, mortalities, recurrences, and cure rates) of PAIR and laparoscopy procedures was used. The meta-analysis and the forest plots of the two procedures show that the PAIR approach is superior in terms of cure, complication, and mortality rates compared with the laparoscopy technique. However, the recurrence rate is low in laparoscopic approaches. Moreover, Egger's tests for determining publication bias and heterogeneity tests were also performed.

Conclusions: This study shows promising trends toward an advantage of PAIR procedures in treatment of liver hydatid cyst in comparison with laparoscopic procedures. The PAIR procedure is superior to laparoscopy due to having a higher cure rate and lower complication and mortality rates; however, the latter has a lower recurrence rate.

Key words: liver, hydatid cyst, echinococcosis, laparoscopy, PAIR, metaanalysis.

\author{
Corresponding authors: \\ Babak Sokouti PhD \\ Biotechnology \\ Research Center \\ Tabriz University \\ of Medical Sciences \\ Daneshgah Street \\ 12345 Tabriz, Iran \\ E-mail: b.sokouti@gmail.com \\ Ramin Sadeghi MD \\ Nuclear Medicine \\ Research Center \\ Mashhad University \\ of Medical Sciences \\ Mashhad, Iran \\ E-mail: raminsadeghi1355@ \\ yahoo.com
}




\section{Introduction}

One of the global diseases threatening human life is hydatid disease, which is caused by tapeworms of the species Echinococcus granulosus [1]. The liver is the most common organ which is infected by this disease (50-70\%) [2]; the second most common organ after the liver is the lung (20-30\%), and the other organs less commonly affected are the spleen, kidneys, heart, bones, central nervous system and other organs [3]. Being asymptomatic is one of the dangerous characteristics of this disease, so the size of the cysts can be increased and after many years they can rupture, which results in anaphylactic shock $[4,5]$. This disease is much more common in endemic regions of countries including Asia, the Middle East, Australia, Mediterranean countries, Europe, and South America; and the rate of incidence is annually more than 50 out of 100,000 persons according to the report of the World Health Organization (WHO) $[1,6,7]$. To diagnose this disease we need to combine some techniques such as imaging, histopathology, nucleic acid detection, and serology [8]. After diagnosing this disease, the physician needs to consider an approach from three known treatments including open surgery, PAIR (Puncture, Aspiration, Injection and Re-aspiration) and laparoscopic surgery (Lap) for hydatid liver cysts [3].

Open surgery, which is used for a complete removal of cysts, is a formal and traditional procedure among the surgeons for treating this disease $[1,9]$. The PAIR procedure is considered one of the noninvasive treatments [10]. This procedure was first presented by Mueller in 1985 [11]. Although this procedure is safe, effective, cheap and easy to perform, it is controversial from the perspective of the association of surgeons [12]. The controversy refers to the disadvantages of this procedure, since it can cause anaphylactic shock, death, and intraperitoneal spillage while performing puncture [13]. However, it has recently been reported that PAIR is the accepted treatment of uncomplicated liver hydatid cysts in the stages of CE1 and CE3a [8].

Laparoscopic surgery is a new surgical technique for liver hydatid cysts that require incision $(0.5-1.5 \mathrm{~cm})$ [14] and was first performed in 1992 [15]. Due to the benefits of this procedure such as small incisions and less postoperative pain, most surgeons might choose it as their first choice, but it can be challenging because of some disadvantages such as being expensive, requiring special devices and experience, being suitable for selected cases, intraperitoneal spillage and shock [15].

There have been many advances and scientific reports on several topics related to systematic review and meta-analysis which are of much interest to evaluate and derive useful information from the outcomes of various approaches in treating diseases in research areas in terms of their clinical efficacy, diagnostic accuracy, and controlling incidence of particular diseases in local or global areas over the world [16-20]. According to the abovementioned information, although WHO confirmed PAIR treatment in some stages, there is a challenge in the selection of new hydatid liver cyst treatment procedures (i.e., laparoscopic surgery and PAIR). To the best of the authors' knowledge, this study is the first time that the two approaches have been compared by performing a systematic review and meta-analysis. Furthermore, based on the PICO (Patients, Intervention, Comparison, Outcomes) statement, the current systematic review and meta-analysis achieves its objective by defining patients who are infected by liver hydatid cysts, the intervention includes the PAIR and Lap procedures to treat the disease, the comparison element answers the question for comparing these procedures in terms of their outcomes, and finally the outcomes of interest consist of cure, postoperative complications, mortality, and recurrence rates of the intervention procedures which need to be increased, decreased, decreased and decreased, respectively.

\section{Material and methods}

Based on the PRISMA (Preferred Reporting Items for Systematic Reviews) guidelines [21], the databases were searched, and the articles related to PAIR and laparoscopic surgery of liver hydatid cyst (conservative and radical) were derived and reviewed.

\section{Search method}

We systematically searched and reviewed two databases, PubMed and Scopus, during the period of January 2000 to December 2016, in order to select and evaluate the relevant published articles.

\section{Data search and extraction}

The Boolean query used for searching the abovementioned databases was as below: ([liver OR hepatic] AND [Echinococcosis OR hydatid]) AND (laparoscop* OR PAIR OR [puncture OR percutaneous] AND aspiration AND injection AND re-aspiration) OR ultrasound.

\section{Inclusion and exclusion criteria}

Inclusion criteria included the English language, retrospective and prospective studies, and some comparative studies of PAIR and laparoscopic treatment research.

Exclusion criteria were as follows: (i) unrelated articles, (ii) studies with inadequate data, (iii) 
non-English language, letters and case report articles, (iv) systematic review, meta-analysis, and duplicated articles. Reported data on the incidence of recurrence, mortality, cure rate and post-procedural complications were stored in an Excel file according to the checklist.

Two researchers independently and separately extracted the data from each study. Extracted data were sample size, mean ages, gender, type of procedures, minor and major complications, recurrence, cure rate, mortality, length of hospital stay and time of operations and Re-PAIR or Re-operation. Additionally, the terms heterogenicity $\left({ }^{2}\right)$ and publication bias were analyzed in both groups.

\section{Patients' characteristics}

Liver hydatid cysts can be confirmed by ultra-sonography, abdominal computed tomography (CT) scans, and serologic methods. Patients whose ages were in the range from 5 to 87 years old with uncomplicated liver hydatid cysts defined as intact non-infected liver hydatid cysts with no biliary system or other viscera communication were considered.

All patients with complicated liver hydatid cysts with clinical signs and suspicion of biliary system or other viscera communication were not selected for any type of treatment (PAIR or Lap).

\section{Interventions}

\section{PAIR procedure}

The PAIR procedure is known as a noninvasive treatment (10). To perform this procedure, cysts are first diagnosed by ultrasound guidance. Then, the cyst is punctured percutaneously by local anesthesia. After that, cystic fluid is aspirated, and scolicidal agents (hypertonic saline, alcohol, Betadine or cetrimide, and others) are injected into the cyst cavity. Finally, after 20 to 30 min the injected solution is re-aspirated [22].

\section{Laparoscopic procedure}

This method is done by laparoscopic instruments, general anesthesia and evacuating hydatid fluid using scolicidal agents with soaked scolicidal gauzes. Then, pericystectomy, omentoplasty, and biliary opening closure in patients with uncomplicated liver hydatid cysts are performed.

\section{Outcome measures}

Successful clinical outcomes are assessed by disappearance of hydatid cysts as well as their cure rates. Postoperative complications, mortality, and recurrence rates of the two abovementioned procedures are taken as clinical hazards. Hospital stays and operative times of the patients, quality of life, and health economics were not recognized as serious events to be meta-analyzed.

Postoperative complications are categorized as minor (i.e., skin rash, pruritus, and anaphylaxis) and major (i.e., infections abscess, bleeding, seeding of cyst communication with intra-biliary system or the need to perform the re-operation or open surgery).

\section{Analysis}

Eligible studies were extracted into a spreadsheet file for analysis. Pooled analysis was performed on studies to calculate event rates. Event rates were used as the effect measure estimate. Meta-analysis was performed with a random effect model. The number of included published articles was 57 (23 for PAIR and 34 for laparoscopic surgery studies). The measures of analysis were postoperative complications, mortality, recurrence, and cure rates of both types of procedures.

We assessed publication bias using funnel plots and Egger's tests. The heterogeneity test was done by quantitative measures including $\mathrm{Q}$, $p$-value, and $l^{2}$. In the presence of heterogeneity, meta-regression was performed and using $\left(R^{2}\right)$ we could determine if published year or sample size explain the heterogeneity or not.

After generating the funnel plots and performing the required regression modeling such as interception of Egger's regression tests and their $p$ values, the publication bias of the study was assessed. Based on various studies for assessing publication bias a $p<0.05$ is regarded as significant. The statistical analysis done on all data was performed using both meta-analysis developed in Mashhad University of Medical Sciences (meta-MUMS) and Comprehensive Meta-analysis (CMA) version 2.2.0.064 [23] while only our implemented software results are presented in this study to show our tool to be an alternative means for CMA in future studies of researchers.

A $p<0.05$ for the heterogeneity test or $12>50 \%$ indicated significant heterogeneity among the studies. In this study, all of the results and their statistical analyses are calculated and obtained from the meta-MUMS tool.

\section{Results}

The potentially relevant studies from initial search criteria returned 2251 titles. Figure 1 represents the literature review search based on PRISMA guidelines. a total of 2832 patients within 57 studies met our inclusion criteria, 34 studies for laparoscopy [3, 5, 9, 15, 24-53] with $n=1182$, and 23 studies for the PAIR approach $[3,54-75]$ with $n=1650$ and therefore were analyzed to evaluate the effects of laparoscopy and 


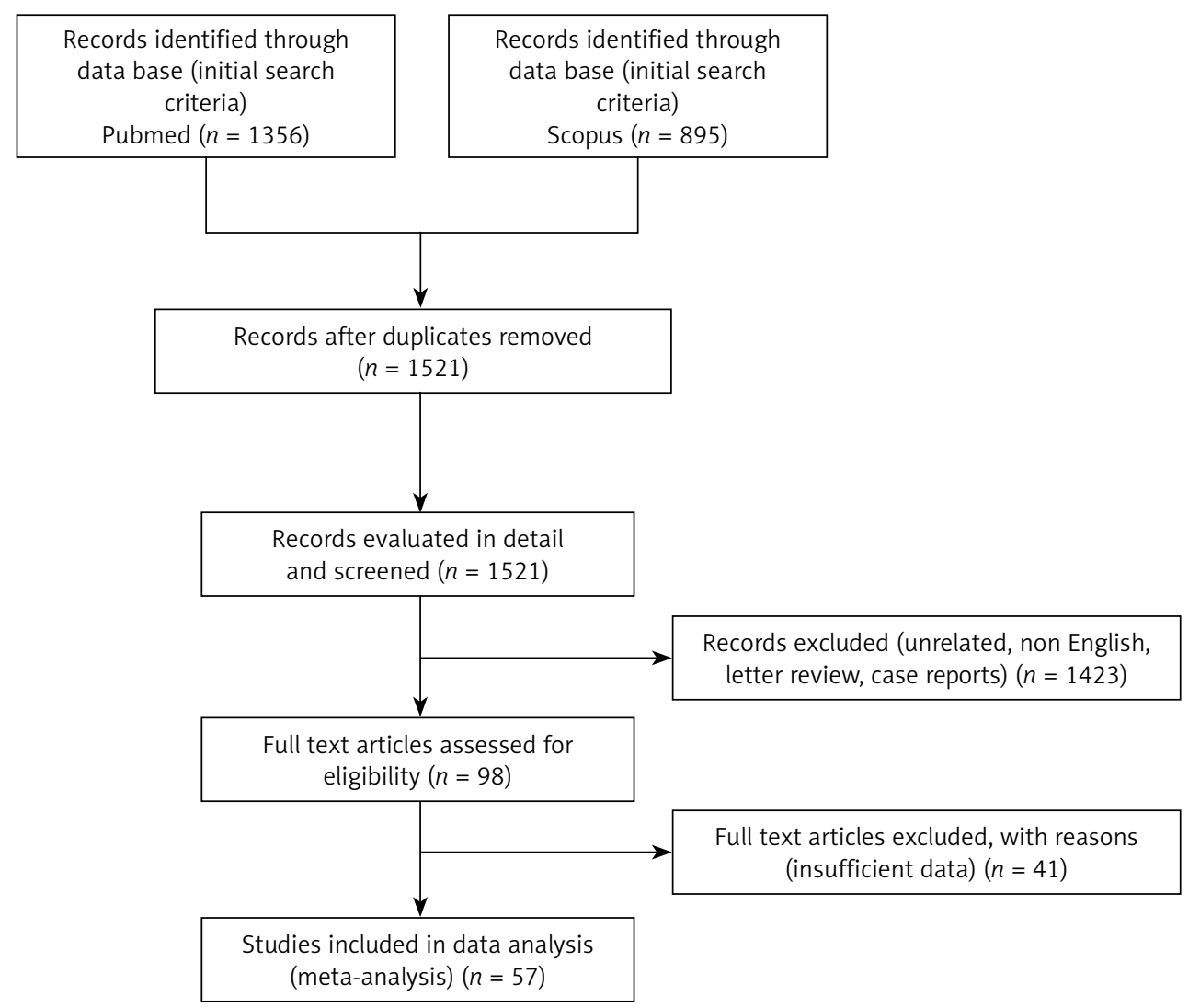

Figure 1. PRISMA flowchart for selecting relevant articles and patients

PAIR techniques on the outcome of treatment of liver hydatid cysts. Of 57 studies, 17 took place in Turkey, 11 in India, 5 in China, 2 in Croatia, 2 in Tunisia, 2 in Chile, 2 in Spain, 2 in Russia, 2 in Ukraine, 2 in Italy, 1 in Romania, 1 in Saudi Arabia, 1 in Pakistan, 1 in Lebanon, 1 in Argentina, 1 in Iraq, 1 in The Netherlands, 1 in Yugoslavia, 1 in Denmark, and 1 in Bosnia Herzegovina. One study [3] reported on both PAIR and laparoscopic groups. It is worth mentioning that the relation of the cysts to the biliary tree is important in the PAIR procedure due to preventing the sclerosing cholangitis effect of some injected scolicidal agents which will be diagnosed by aspiration. However, all studies included in this research followed this principle.

Six (of 57) studies [26, 27, 37, 39, 40, 52] were prospective and the remaining ones were retrospective studies. Ages and operating times of the two procedures and hospital stays are not mentioned clearly in some studies, so they were not analyzed. The information from the extracted articles from the databases based on the Boolean query where the Lap and PAIR treatments of liver hydatid cysts are included is listed in Tables I and II. Moreover, Tables I and II show the characteristics, demographics, type of procedures, and outcomes of the two abovementioned procedures. Also, Figure 2 displays forest plots of these two procedures.
The random effect meta-analysis of cure rate outcomes in PAIR and laparoscopy procedures are as follows:

Random effect meta-analysis of PAIR: event rate $=0.928,95 \% \mathrm{Cl}$ lower limit $=0.89$, upper limit $=0.953, Z=10.951, p<1 \mathrm{e}^{-16}$. The forest plot is illustrated in Figure $2 \mathrm{~A}$.

Random effect meta-analysis of laparoscopy: event rate $=0.907,95 \% \mathrm{Cl}$ lower limit $=0.859$, upper limit $=0.940, Z=9.431, p<1 \mathrm{e}^{-16}$. The forest plot is illustrated in Figure $2 \mathrm{~B}$.

The inconsistency and heterogeneity parameters can also be estimated by quantitative measures in both groups. The results of the heterogeneity test of the PAIR procedure are $Q=75.067$, $\mathrm{d} f=22, p=1.031 \mathrm{e}^{-7}, p^{2}=70.693, \Gamma^{2}=0.706$, and hence it has high heterogeneity. The results of the heterogeneity test of the laparoscopy procedure are $Q=122.575, \mathrm{~d} f=33, p=3.133 \mathrm{e}^{-12}, l^{2}=$ $73.078, \Gamma^{2}=1.203$, and therefore it also has high heterogeneity. However, in both heterogeneity tests, the $p$-values were significant.

Meta-regression was performed using a random effect model in the PAIR procedure based on the published years and sample sizes of the studies. In the meta-regression of the "published year", slope $=0.00028, \mathrm{SE}=0.04716, p=0.99535$, $\Gamma^{2}=0.75470, p$-value is not significant so there is no relation between published year and PAIR 


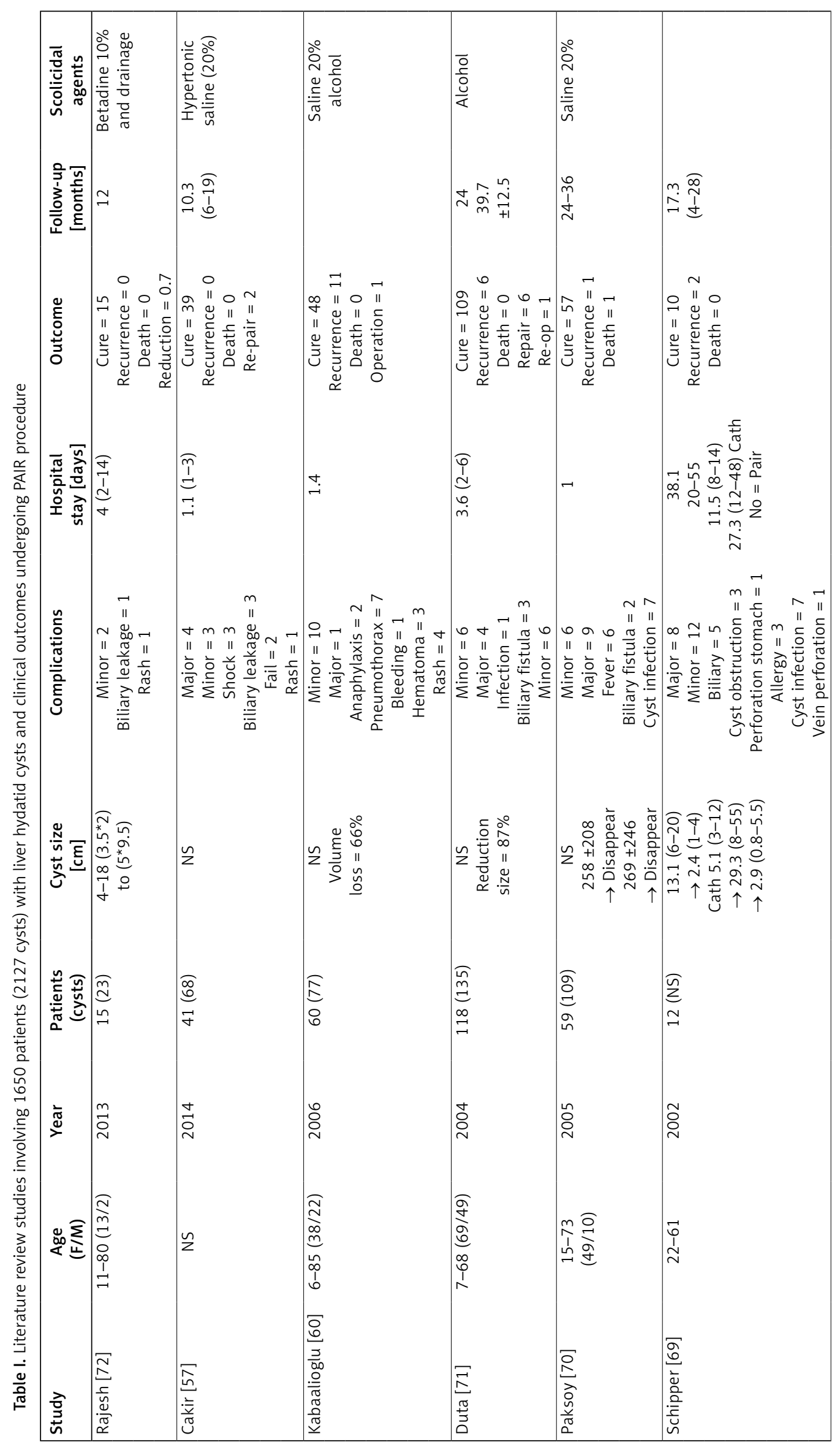




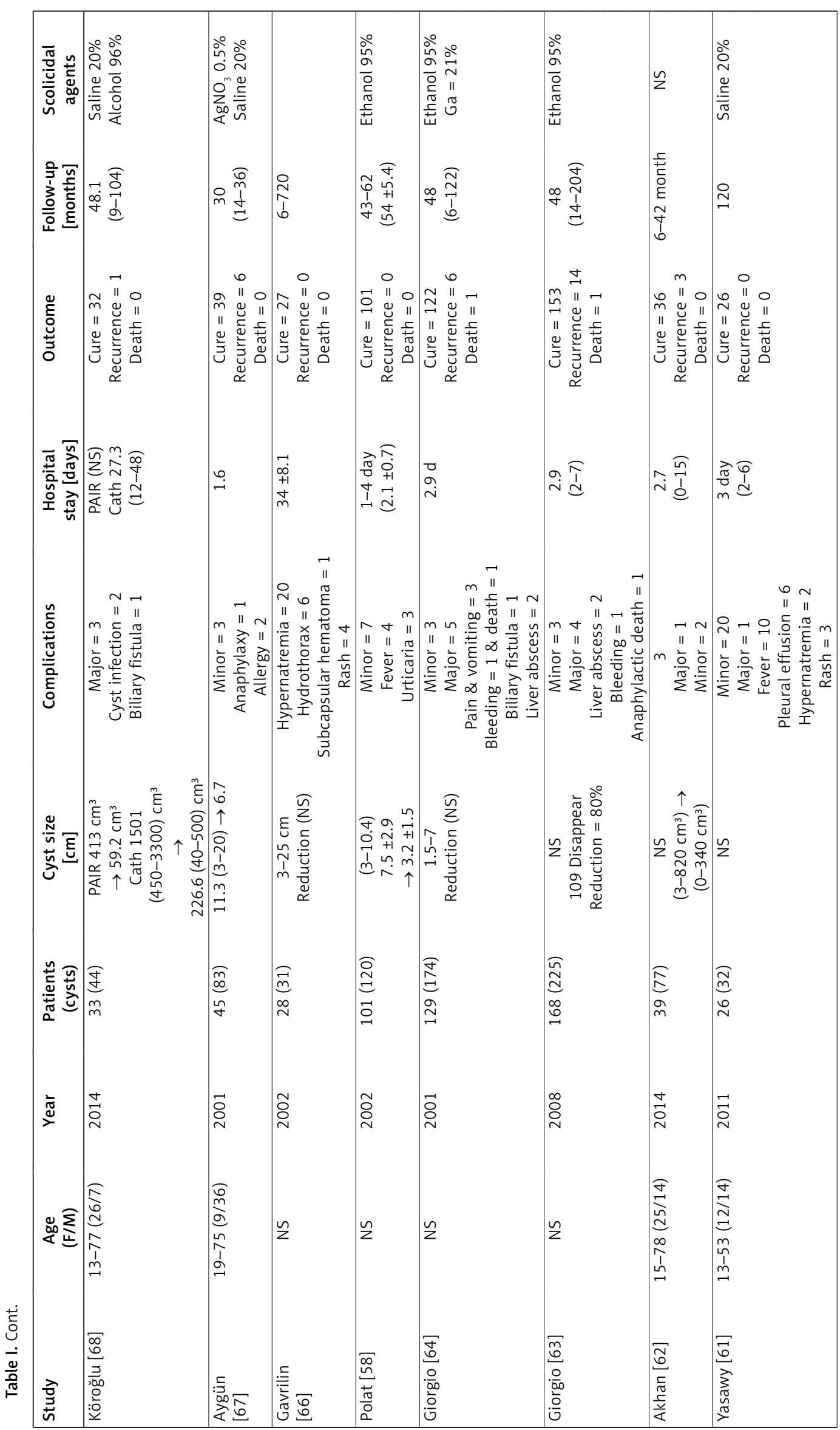




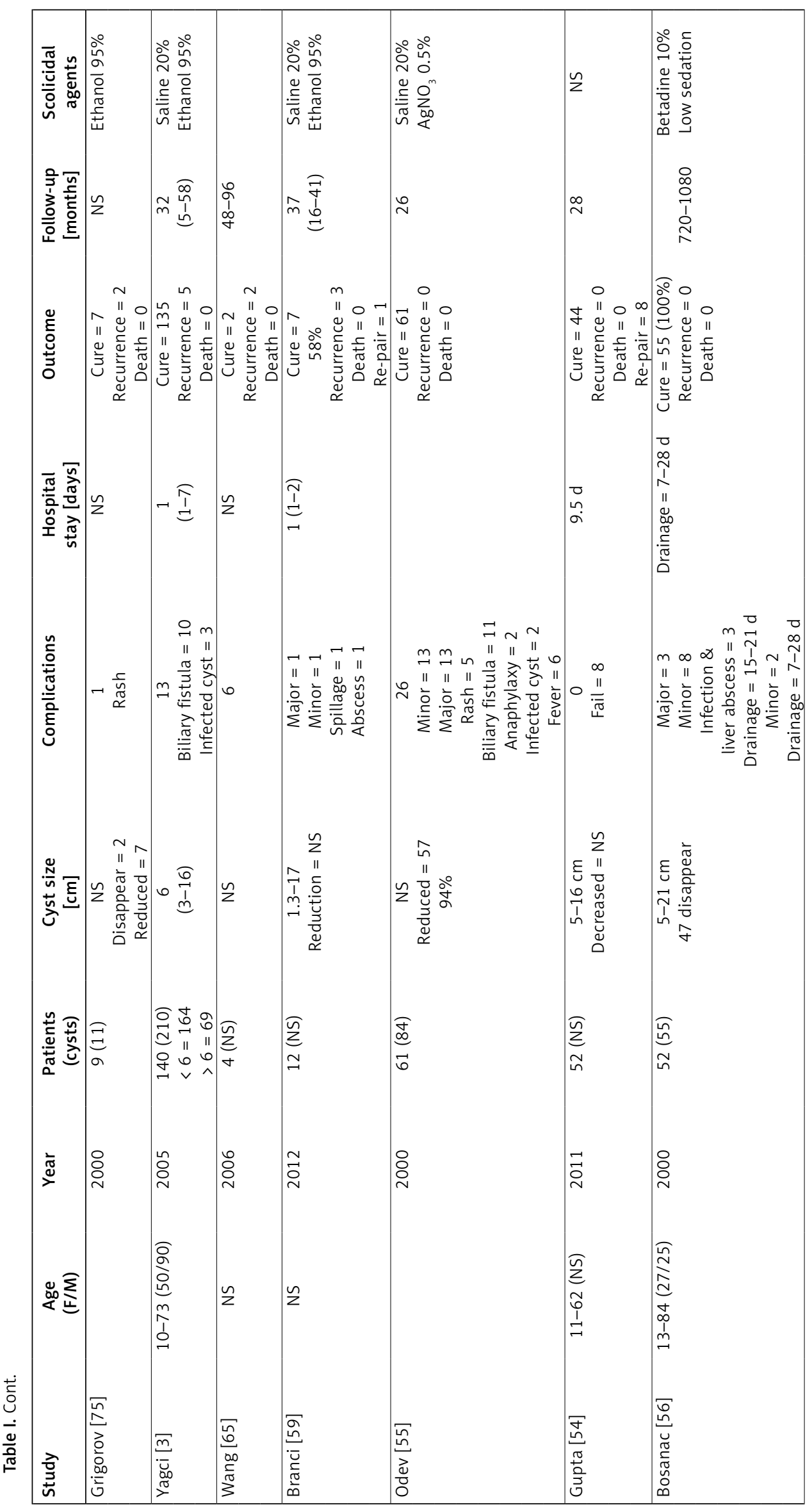



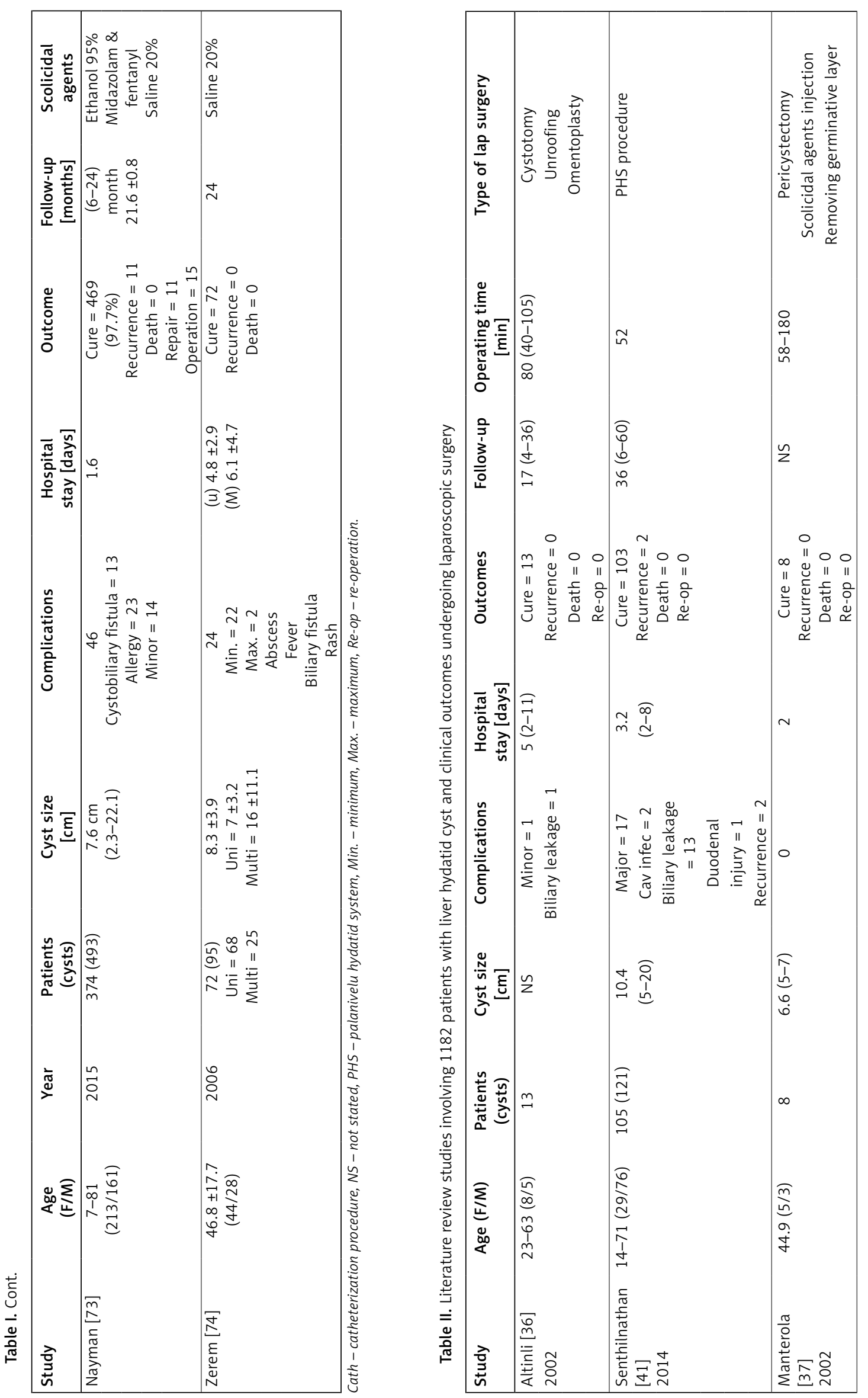


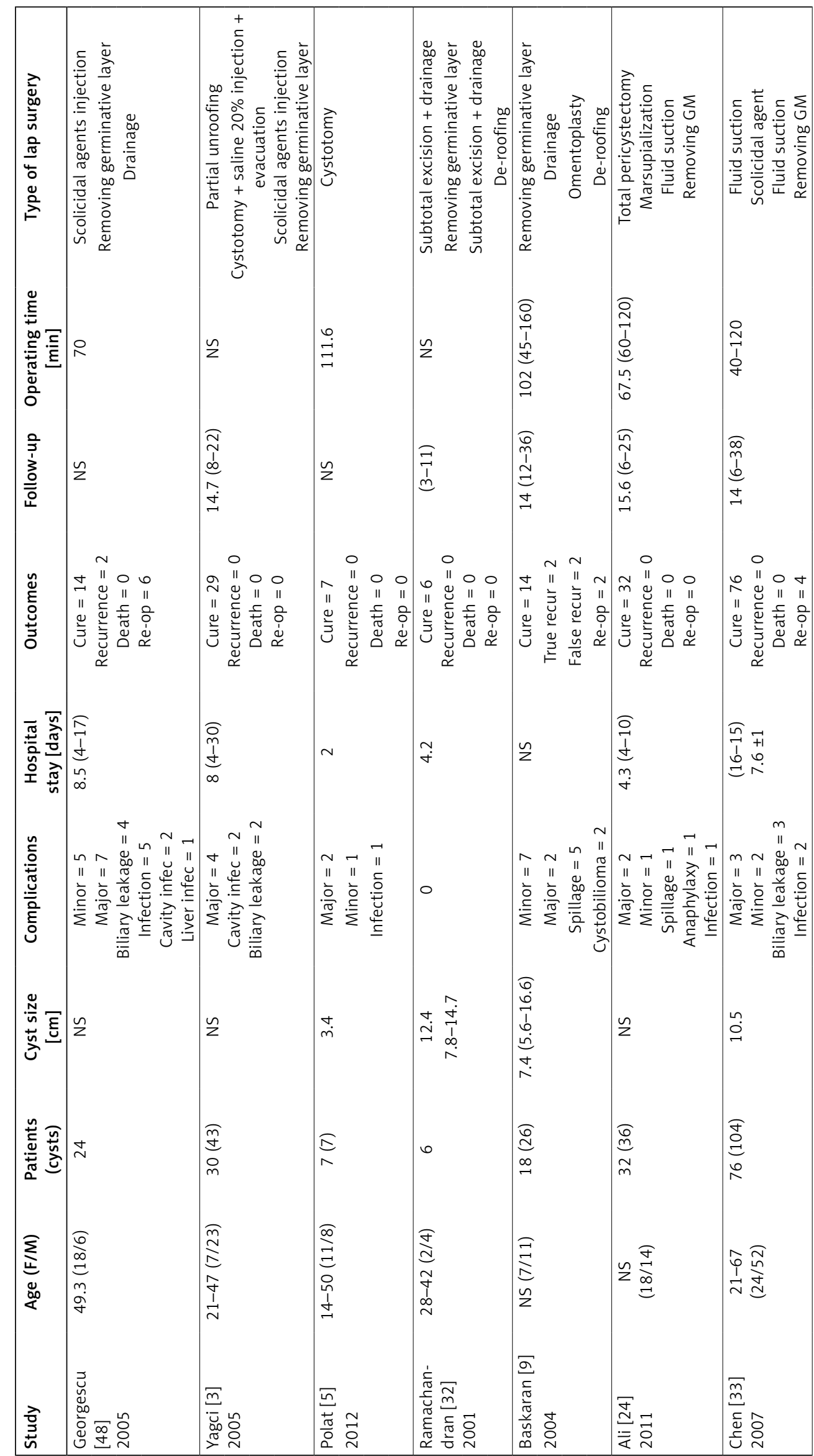




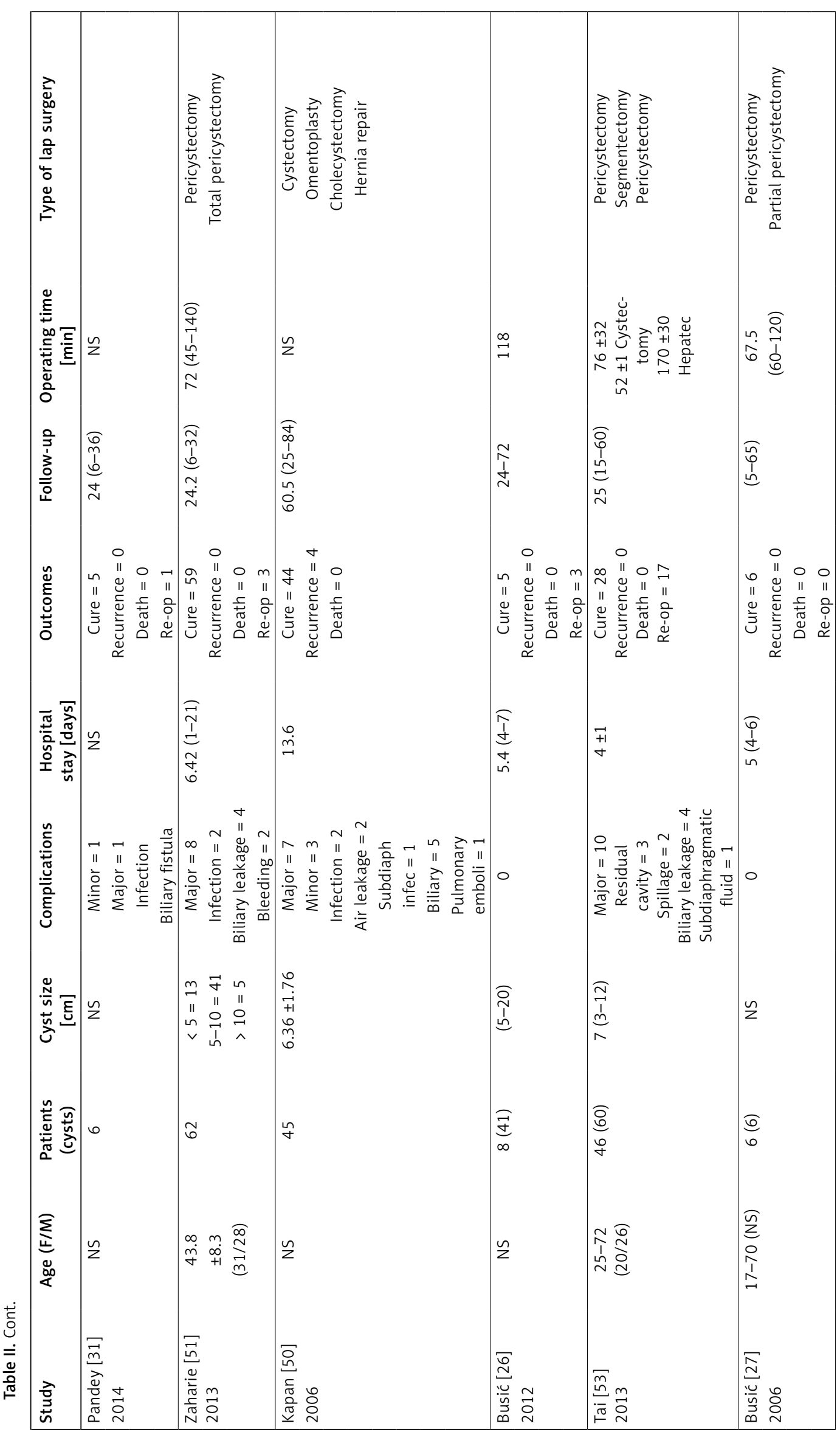




\begin{tabular}{|c|c|c|c|c|c|c|c|c|}
\hline 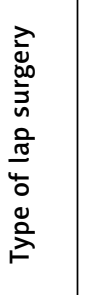 & 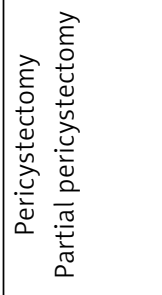 & 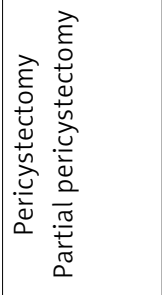 & & 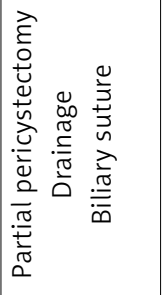 & 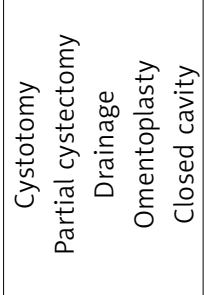 & 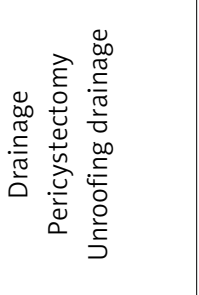 & & 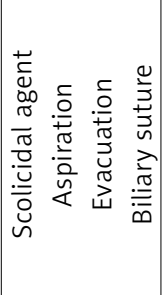 \\
\hline 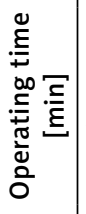 & $\begin{array}{l}a \\
0 \\
0 \\
1 \\
1 \\
0 \\
0 \\
\\
\exists\end{array}$ & $\begin{array}{ll}m & 0 \\
\infty & 0 \\
\infty & 1 \\
n & 0 \\
-1 & 0\end{array}$ & & $\infty$ & 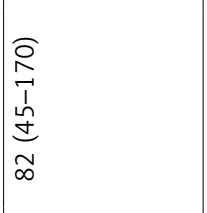 & 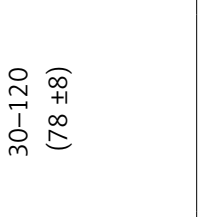 & 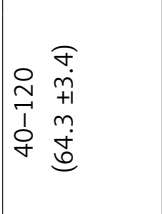 & $\tilde{z}$ \\
\hline \begin{tabular}{l}
0 \\
\multirow{3}{3}{} \\
o \\
훈
\end{tabular} & 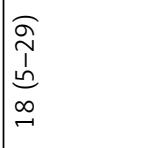 & 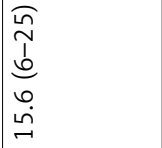 & 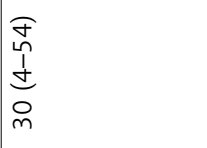 & $\stackrel{\infty}{N}$ & $\stackrel{\sim}{\stackrel{m}{m}}$ & $\begin{array}{l}\underset{N}{N} \\
i \\
n \\
a \\
a\end{array}$ & & $\begin{array}{l}\tilde{N} \\
\ddot{1} \\
\stackrel{\sim}{f}\end{array}$ \\
\hline 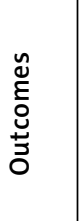 & 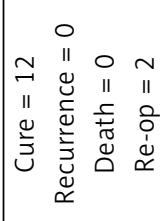 & 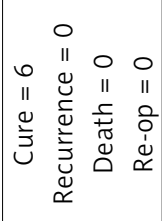 & 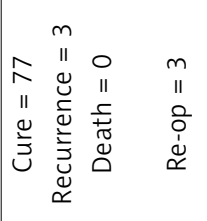 & 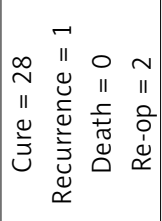 & 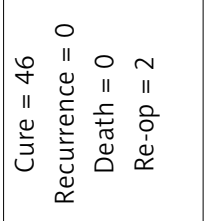 & 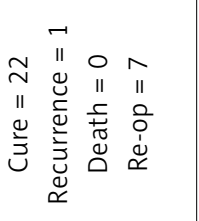 & 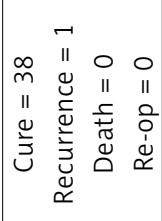 & 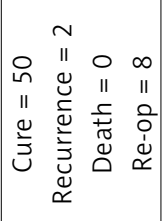 \\
\hline 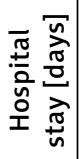 & $\begin{array}{l}0 \\
0 \\
\stackrel{1}{d}\end{array}$ & $\begin{array}{l}0 \\
0 \\
\overrightarrow{1} \\
\dot{d} \\
m \\
0 \\
0\end{array}$ & $\begin{array}{l}\mathbb{a} \\
\stackrel{1}{d} \\
m\end{array}$ & 0 & $\stackrel{\sim}{\sim}$ & 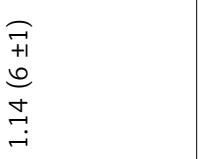 & & $\tilde{z}$ \\
\hline 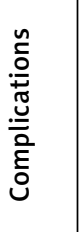 & 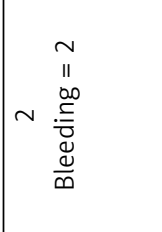 & 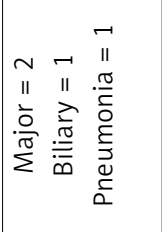 & 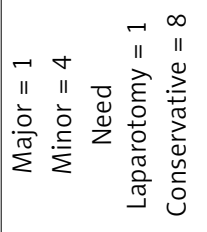 & 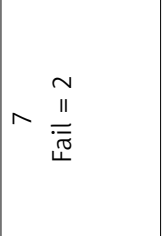 & $m \tilde{z}$ & 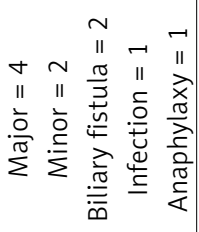 & 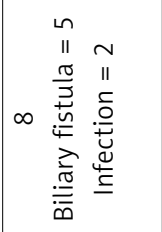 & 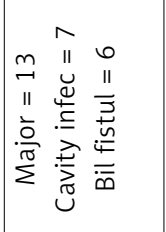 \\
\hline 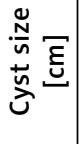 & $\vec{\infty}$ & $\tilde{z}$ & $\tilde{z}$ & $\tilde{z}$ & $\Sigma$ & 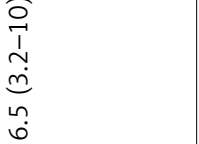 & $\tilde{z}$ & $\tilde{z}$ \\
\hline 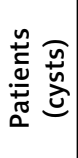 & $\stackrel{\nabla}{\sqsupset}$ & $\begin{array}{l}0 \\
0\end{array}$ & 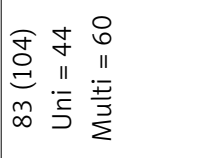 & 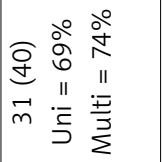 & 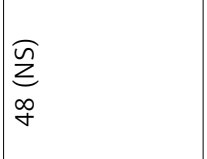 & 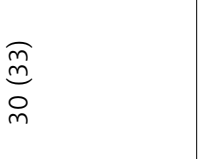 & 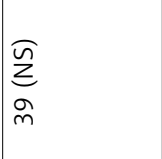 & 8 \\
\hline 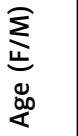 & $\tilde{z}$ & $\Sigma$ & 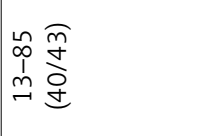 & 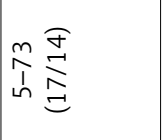 & $\tilde{z}$ & $\Sigma$ & 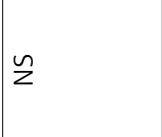 & $\tilde{z}$ \\
\hline 忞 & 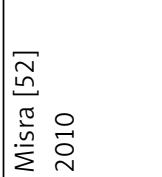 & 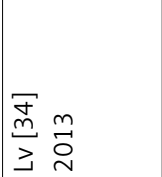 & 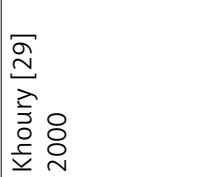 & 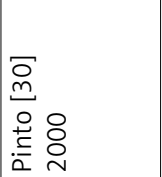 & 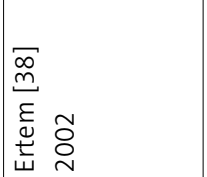 & 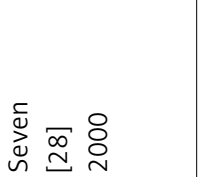 & 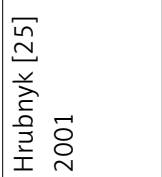 & 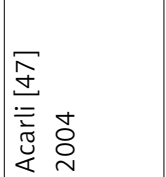 \\
\hline
\end{tabular}




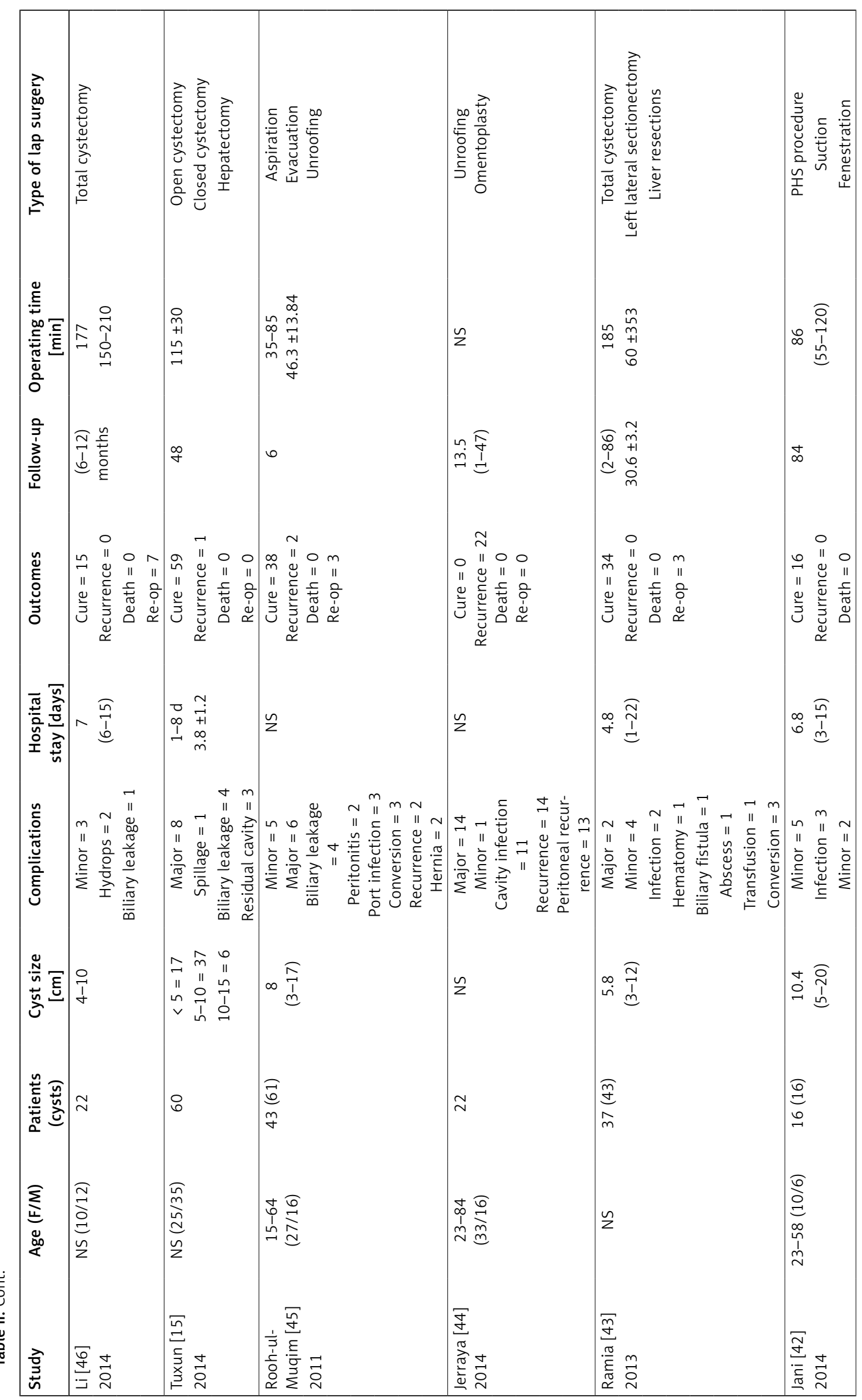




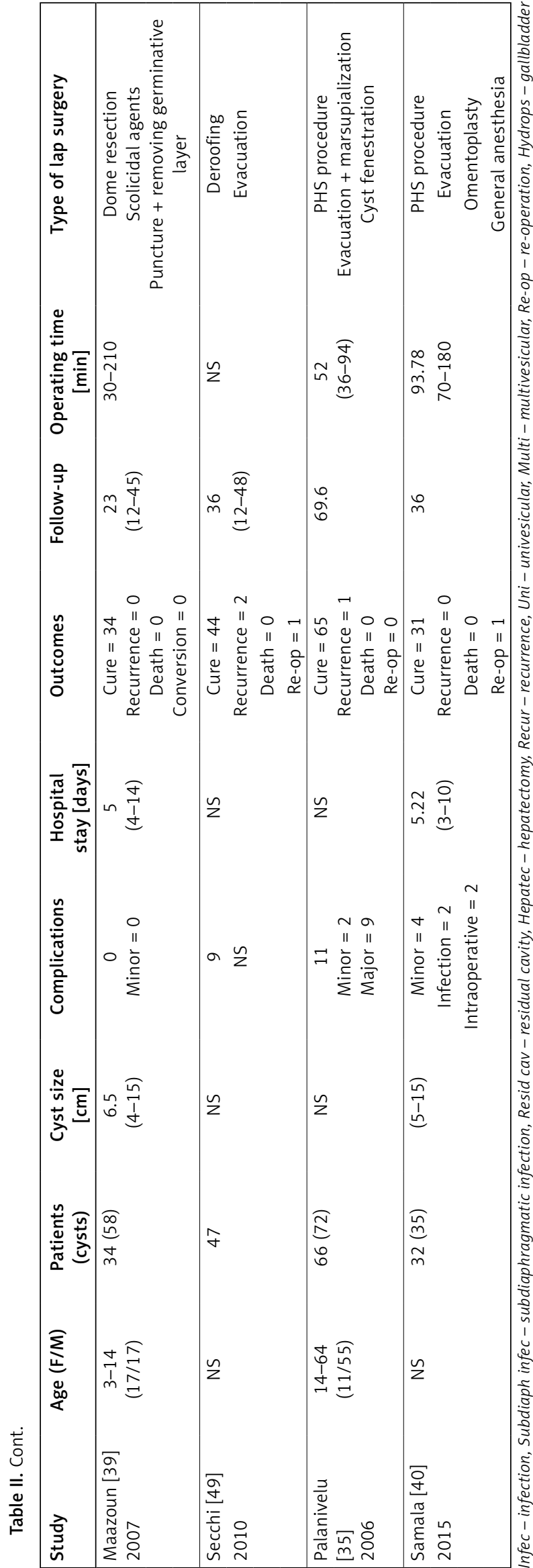

cure rate (Figure $3 \mathrm{~A}$ ) but in the meta-regression of the sample size slope $=0.00516, \mathrm{SE}=0.00215$, $p=0.01625, \Gamma^{2}=0.43135$ (Figure 4 A), which means that the greater the sample size, the higher the cure rate.

Additionally, the meta-regression was performed by the random effect model in the Lap procedure based on published years and sample sizes of the studies. In the meta-regression of "published year", slope $=-0.0234, \mathrm{SE}=0.04769$, $p=0.624, \Gamma^{2}=1.2862$ (Figure $3 \mathrm{~B}$ ). The $p$-value is not significant so there is no relation between published year and cure rate of the Lap procedure. However, in the meta-regression of sample size, slope $=0.0239$, SE $=0.00945, p=0.01136$, $\Gamma^{2}=0.98179$ (Figure $4 \mathrm{~B}$ ). The sign of the slope and significance of the $p$-value show that there is a direct relationship between sample size and cure rate.

Sample size of PAIR and Lap procedures can explain $39 \%$ and $18.4 \%$ of heterogeneities while published year cannot explain the heterogeneity in either procedure.

The funnel plots of the two procedures are shown in Figures $5 \mathrm{~A}$ and $\mathrm{B}$. The result of the meta-analysis for publishing bias, including Egger's regression test with intercept 0.950 and $p=0.244$, does not show any significant publication biases in the PAIR approaches, while the results of Egger's tests with intercept 2.216 and $p=0.00095$ show a publication bias in laparoscopic procedure (Table III).

The meta-analysis random effect model indicates that the cure rate of PAIR is better than the laparoscopic procedure (92.8\% vs. $90.7 \%$, respectively).

\section{Postoperative complications}

Figures $2 \mathrm{C}$ and $\mathrm{D}$ display forest plots of these two procedures. Results of random effect meta-analysis of postoperative complications in PAIR and laparoscopy procedures are as follows: Random effect meta-analysis of PAIR procedure: event rate $=0.185,95 \% \mathrm{Cl}$ lower limit $=0.122$, upper limit $=0.271, Z=-5,938, p=2.89 \mathrm{e}^{-9}$. Random effect meta-analysis of laparoscopy: event rate $=0.187,95 \% \mathrm{Cl}$ lower limit $=0.148$, upper limit $=0.233, Z=-10.316, p<1 \mathrm{e}^{-16}$.

The inconsistency and heterogeneity parameters can be predicted by quantitative measures in both groups. Heterogeneity of PAIR procedure is $Q=192.381, \mathrm{~d} f=22, p<1 \mathrm{e}^{-16}, l^{2}=88.564$, $\Gamma^{2}=1.102$, and so it has high heterogeneity.

Meta-regression was performed using the random effect model based on published year of PAIR procedure where slope $=-0.04371$, $\mathrm{SE}=0.04993, p=0.38136, \Gamma^{2}=1.207$ (Figure 3C). The $p$-value is not significant so there is no relation between published year and PAIR com- 
A

Meta-analysis of event rate with $95 \%$ confidence interval
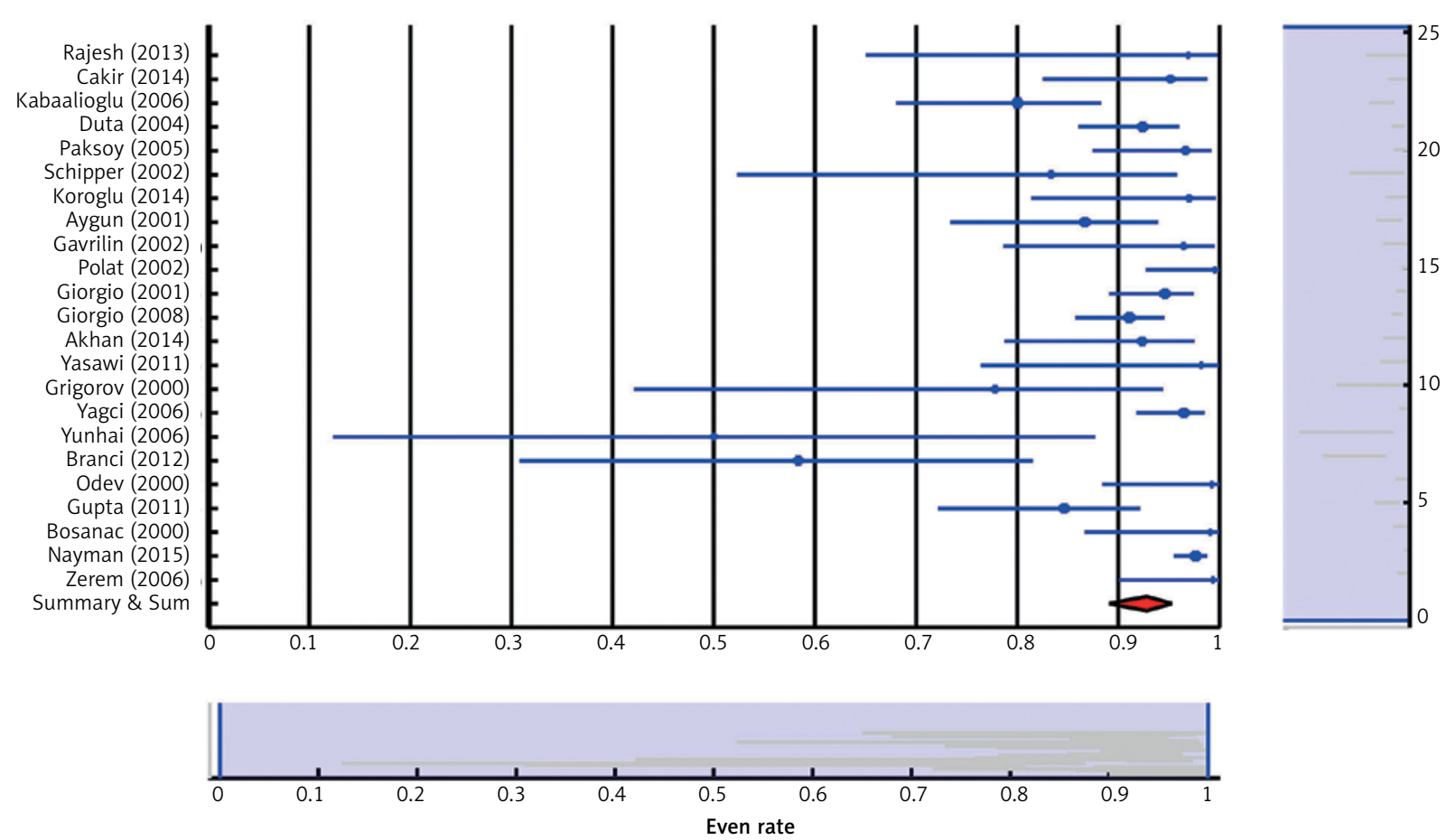

B

Meta-analysis of event rate with $95 \%$ confidence interval
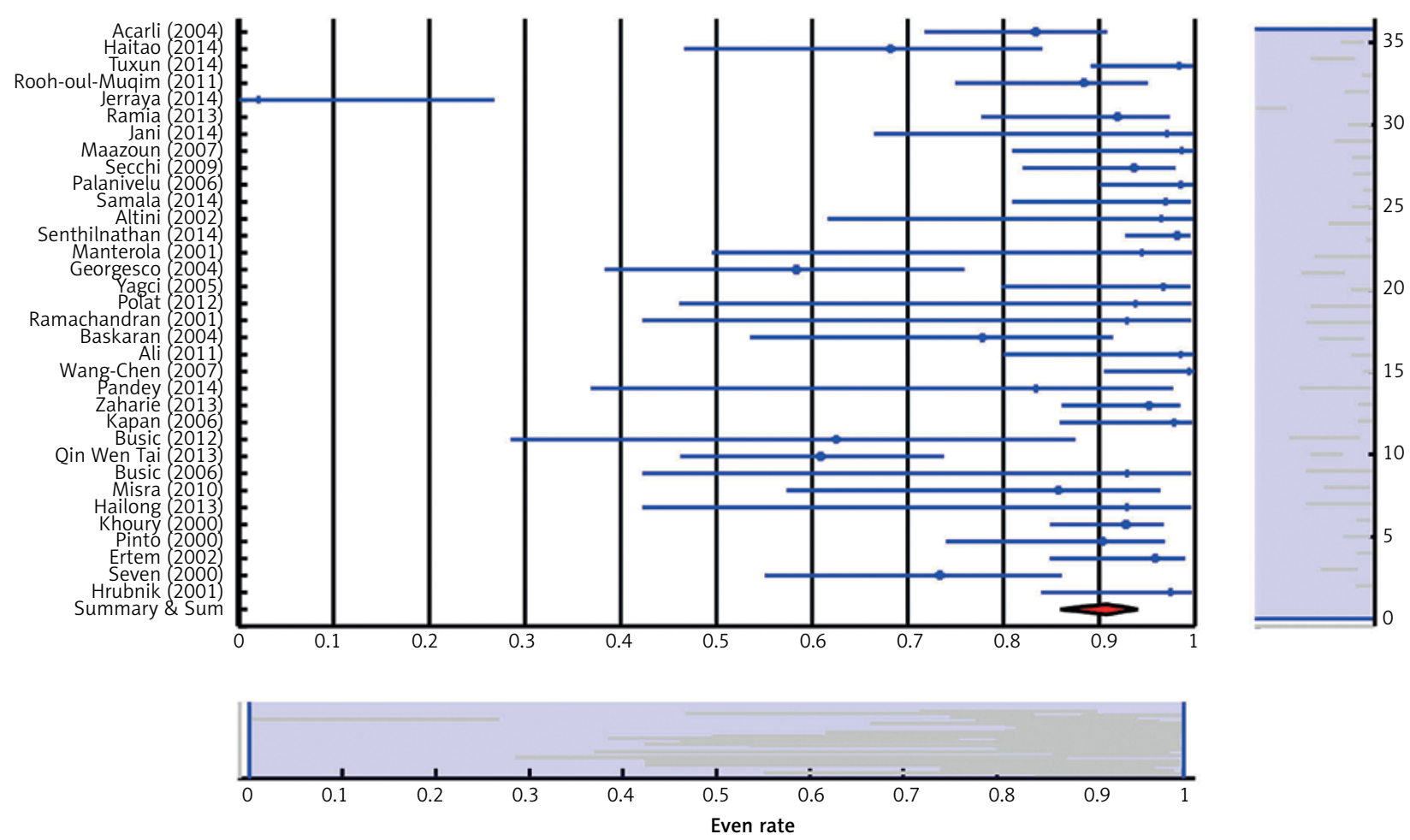

Figure 2. Forest plots of two procedures (A, C, E, G - forest plots of cure rates, postoperative complications, mortalities, and recurrences of PAIR group; B, D, F, H - forest plots of cure rates, postoperative complications, mortalities, and recurrences of Lap procedure) 
C
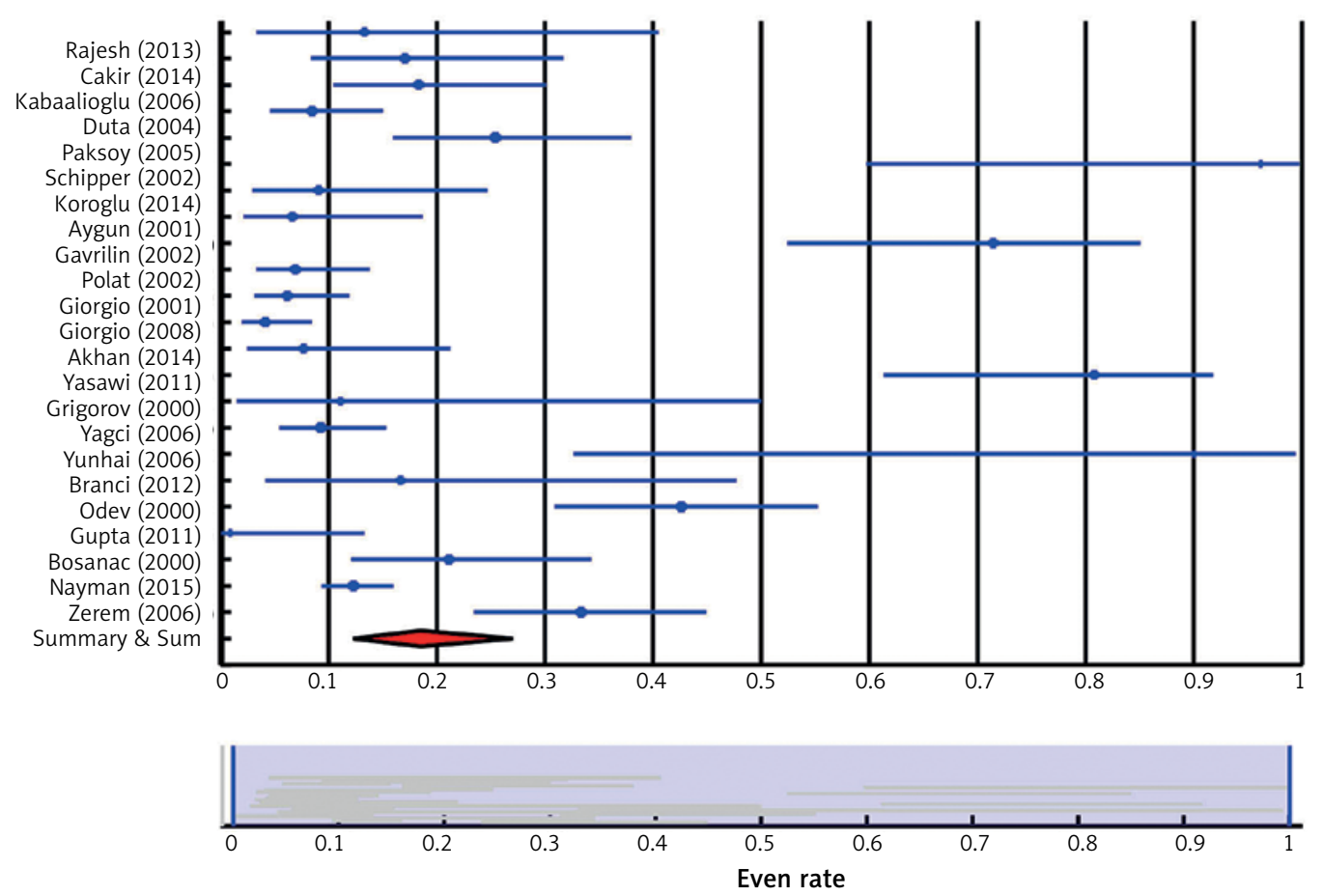

D Meta-analysis of event rate with $95 \%$ confidence interval
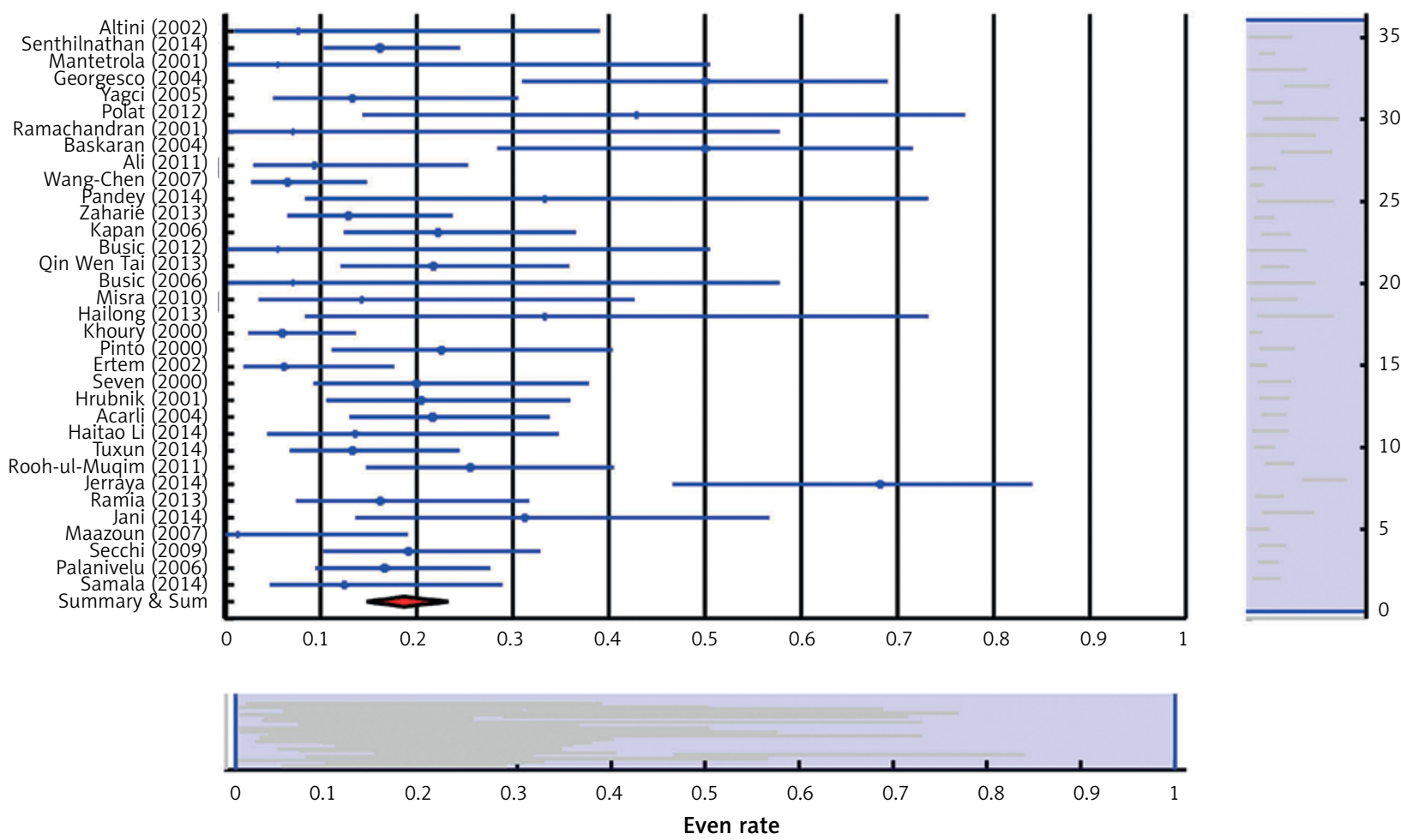

Figure 2. Cont. 
$E$

Meta-analysis of event rate with $95 \%$ confidence interval
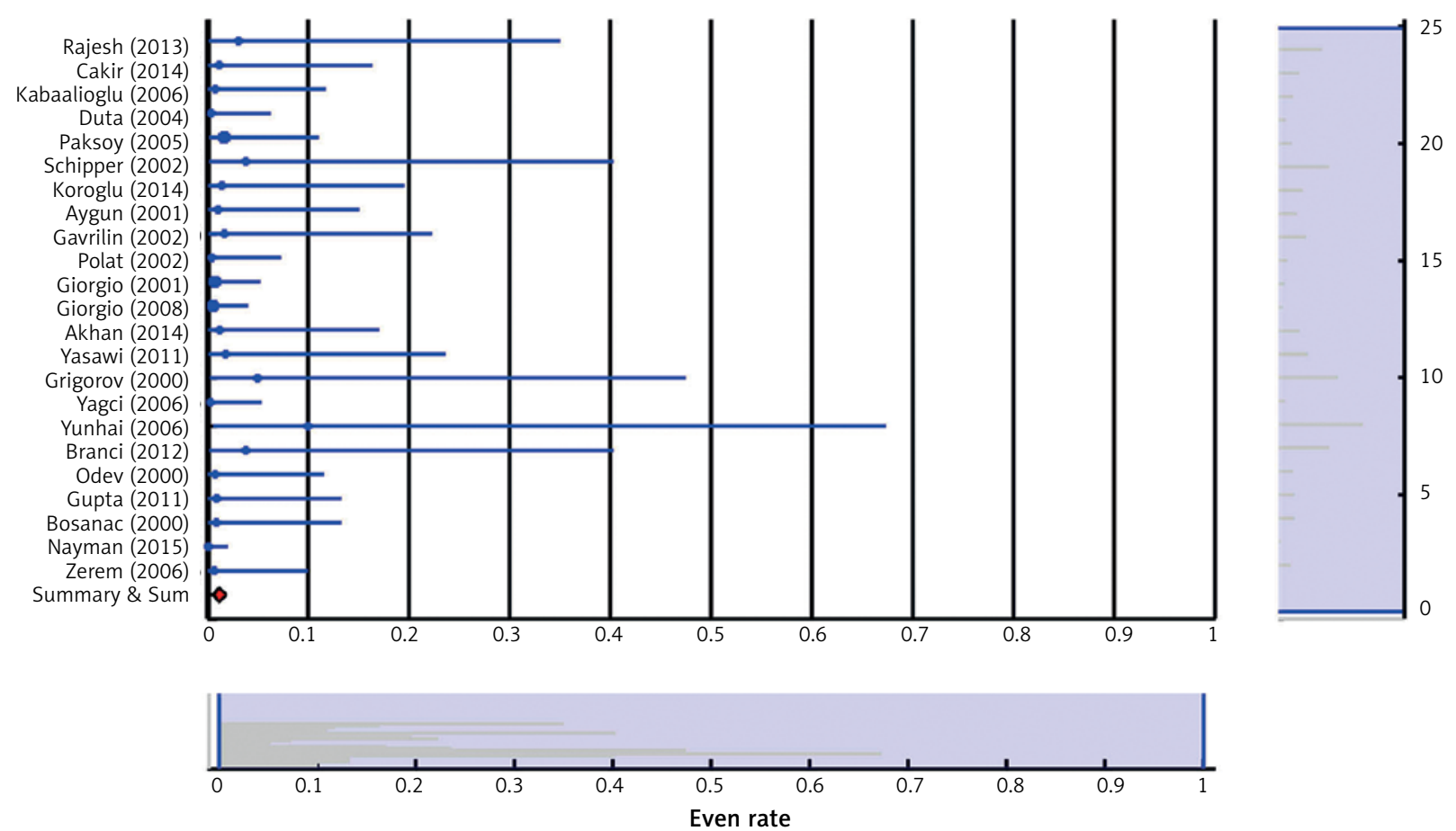

F

Meta-analysis of event rate with $95 \%$ confidence interval
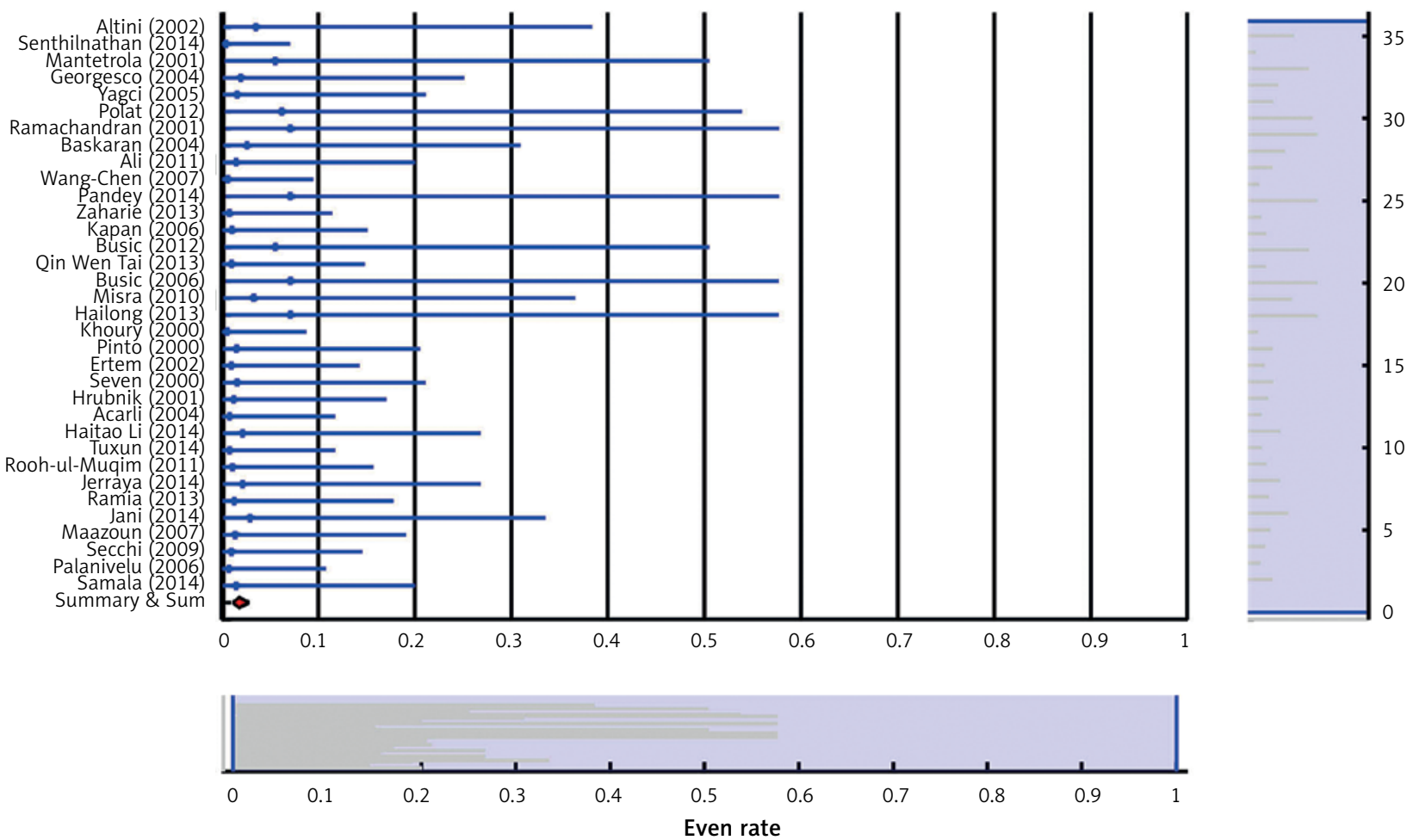

Figure 2. Cont. 
G Meta-analysis of event rate with $95 \%$ confidence interval
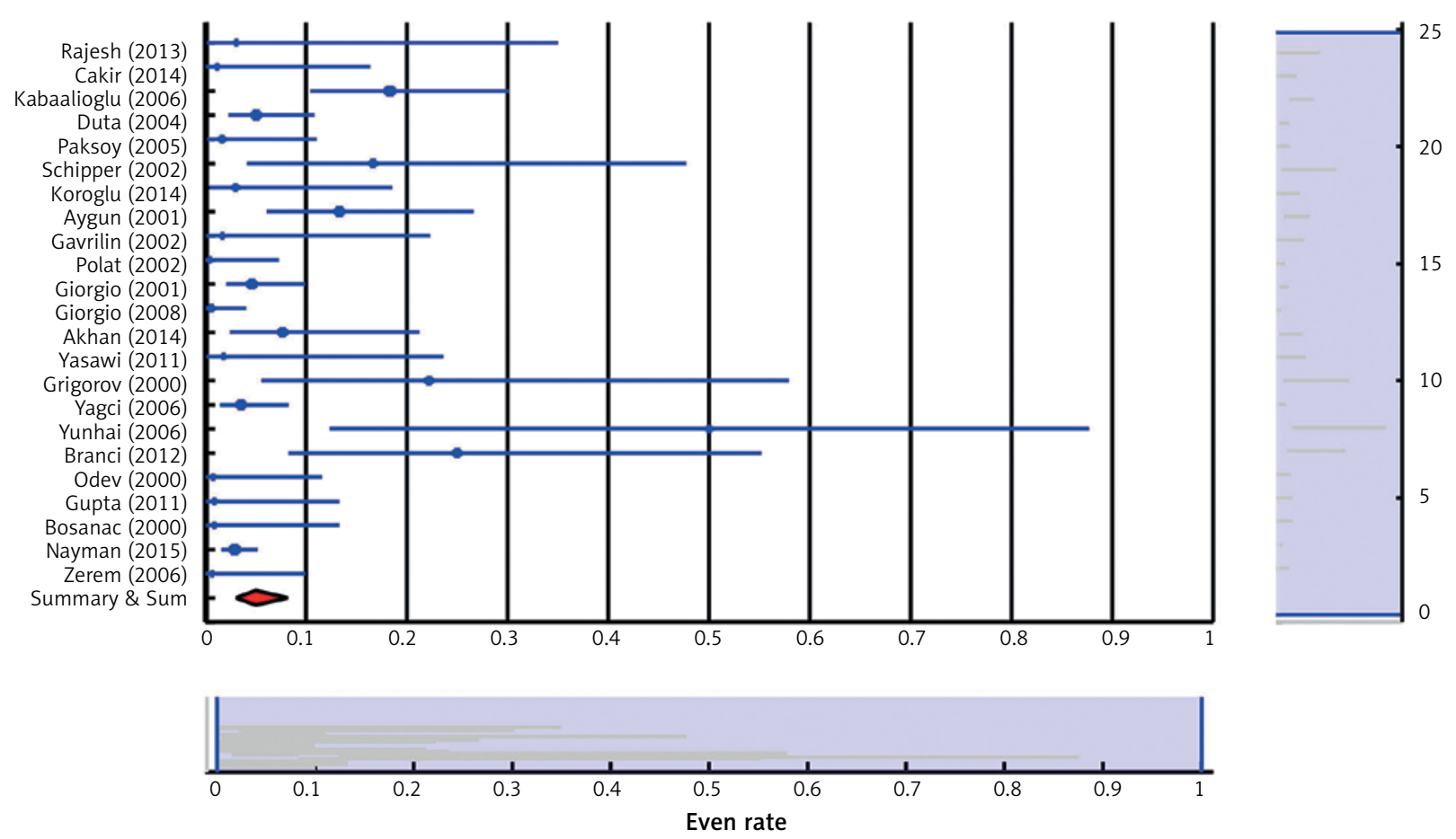

H Meta-analysis of event rate with $95 \%$ confidence interval
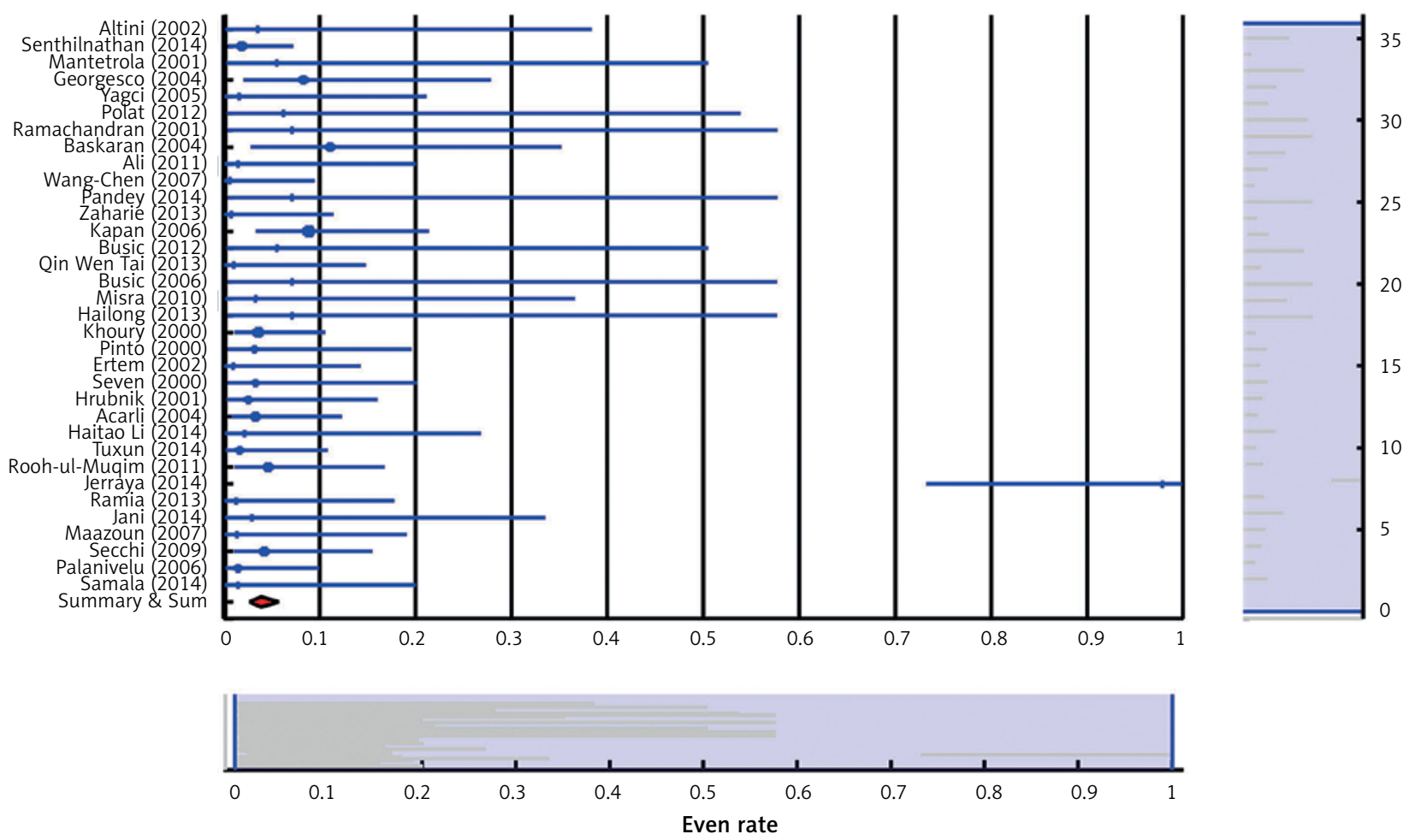

Figure 2. Cont. 
plication rate. However, in thet meta-regression of sample size, slope $=-0.00598$, SE $=0.00307$, $p=0.05130, \Gamma^{2}=1.1551$ (Figure $4 \mathrm{C}$ ); the $p$-value is not significant, so there is no relationship between sample size and complication rate.

Heterogeneity of laparoscopy procedure is $Q=87.486, \mathrm{~d} f=33, p=8.155 \mathrm{e}^{-7}, l^{2}=62.208$, $\Gamma^{2}=0.373$ and it has a medium heterogeneity.

Meta-regression based on "published year" of studies of laparoscopy procedure was performed using a random effect model (slope $=0.02821$,

A

Random meta regression with $95 \%$ confidence interval

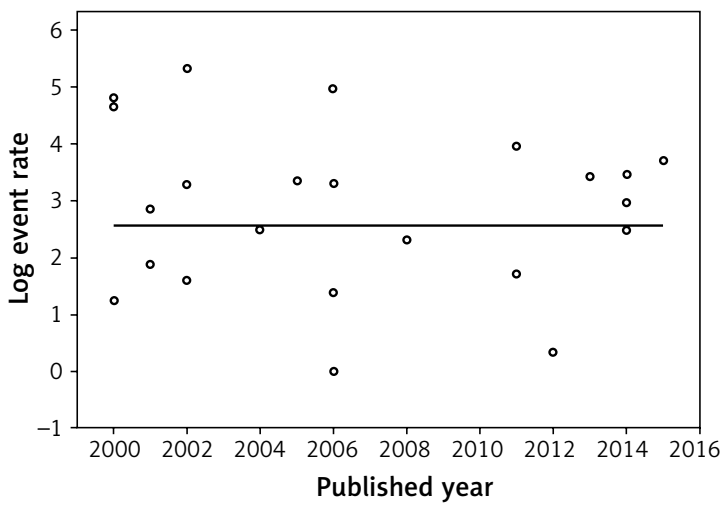

C

Random meta regression with $95 \%$ confidence interval

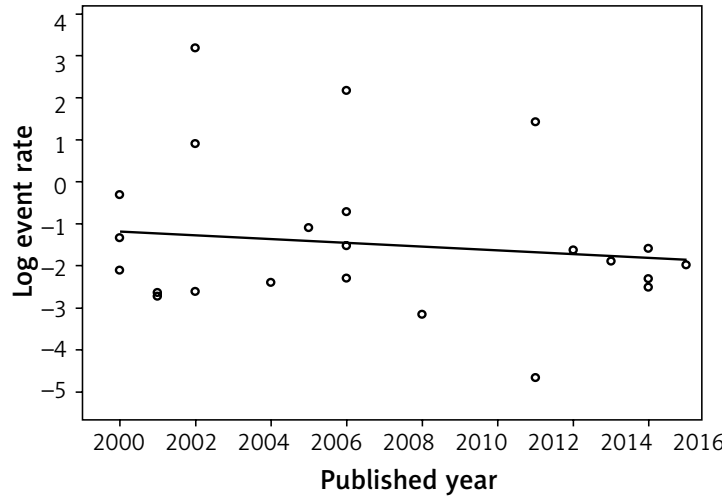

E

Random meta regression with $95 \%$ confidence interval

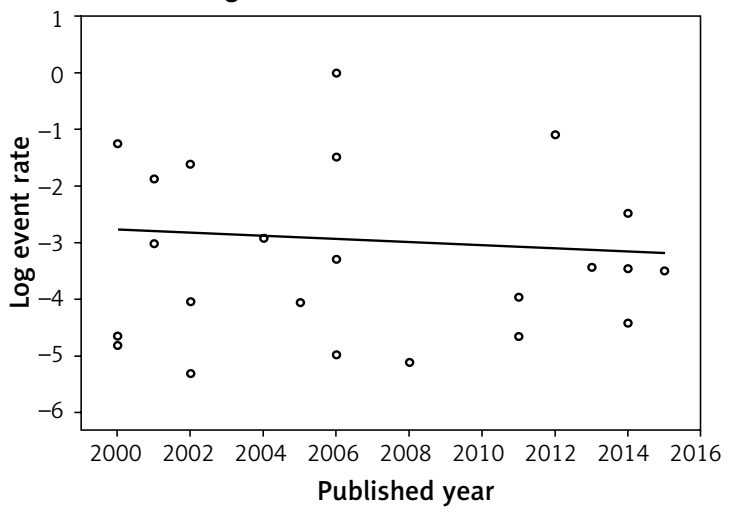

$\mathrm{SE}=0.02837, p=0.32006, \Gamma^{2}=0.3948$; Figure $\left.3 \mathrm{D}\right)$ that showed no relationship between complication rate and published year because the $p$-value was not significant. In sample size meta-regression studies of the laparoscopy procedure using a random effect model (slope $=-0.01365$, SE $=0.00539$, $p=0.01141, \Gamma^{2}=0.28204$; Figure $4 \mathrm{D}$ ) the sign of the slope and significance of the $p$-value show that sample size and complications are inversely related.

Published years of studies of PAIR and Lap procedures cannot explain the heterogeneities while

B

Random meta regression with $95 \%$ confidence interval

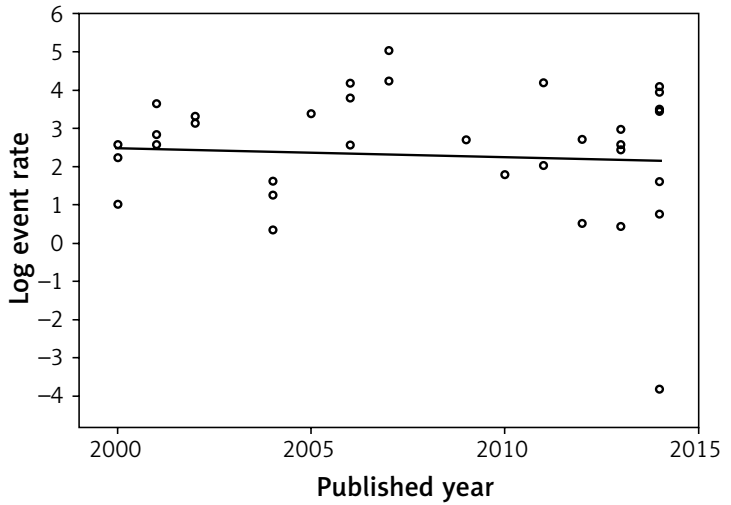

D

Random meta regression with $95 \%$ confidence interval

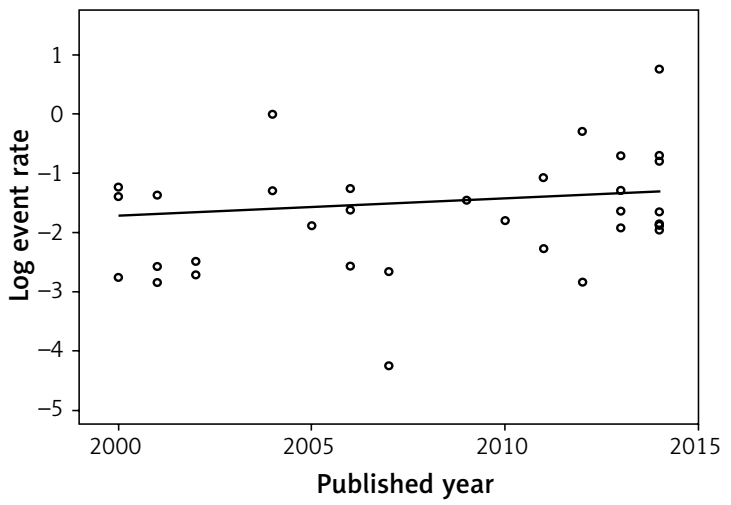

Figure 3. Meta-regression of two procedures: relation between (log cure, complications, and recurrences) and published year (A, C, E) for PAIR procedures (B, D), and Lap procedures 
A

Random meta regression with $95 \%$ confidence interval

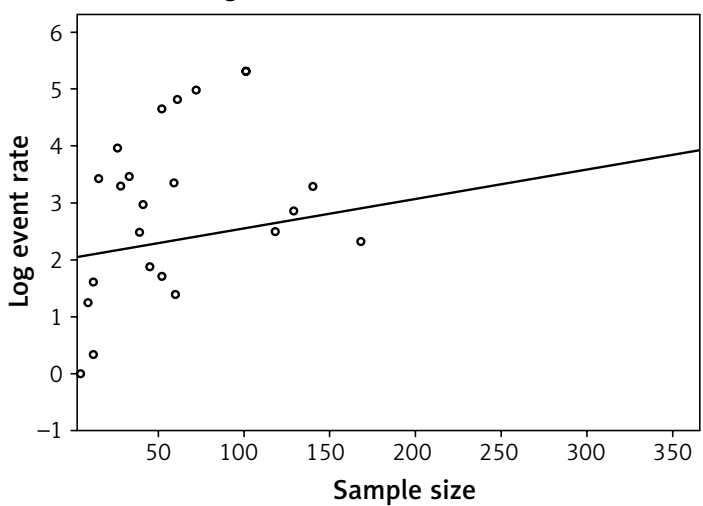

C

Random meta regression with $95 \%$ confidence interval

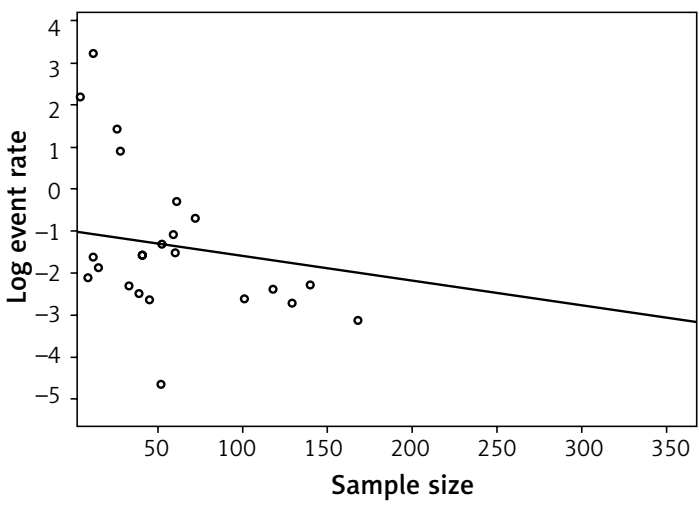

E

Random meta regression with $95 \%$ confidence interval

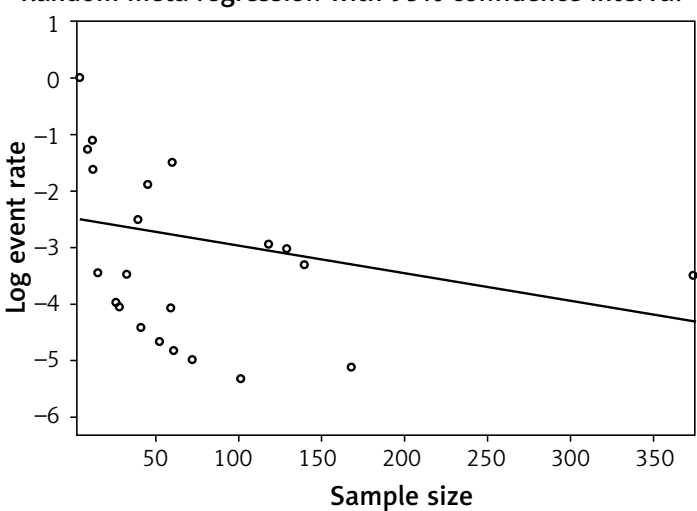

sample size studies of PAIR and Lap procedures $\left(R^{2}=0\right.$ and $\left.R^{2}=0.244\right)$ can explain only $24.4 \%$ of heterogeneity in Lap procedure complications.

The funnel plots of the two procedures are shown in Figures $5 \mathrm{C}$ and $\mathrm{D}$. The result of the metaanalysis for publication bias including Egger's regression test with intercept 0.521 and $p$-value 0.698 in the PAIR approach and also the test result on laparoscopy technique with intercept 0.826 and $p=0.266$ indicate no proof of publication bias in either procedure (Table III).
B

Random meta regression with $95 \%$ confidence interval

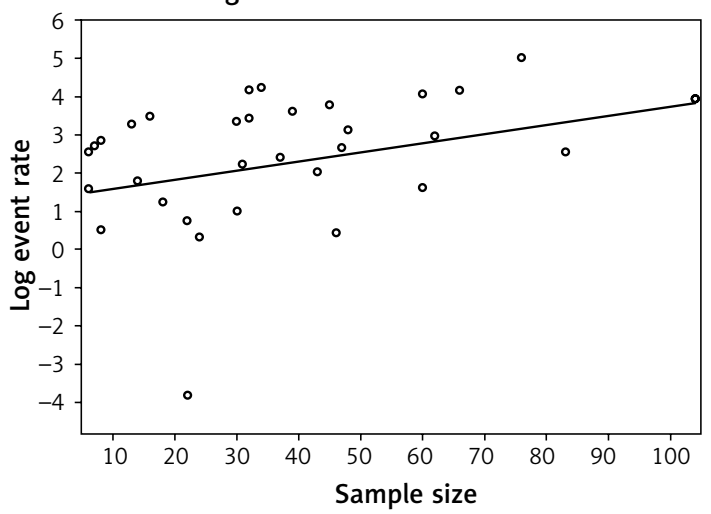

D

Random meta regression with $95 \%$ confidence interval

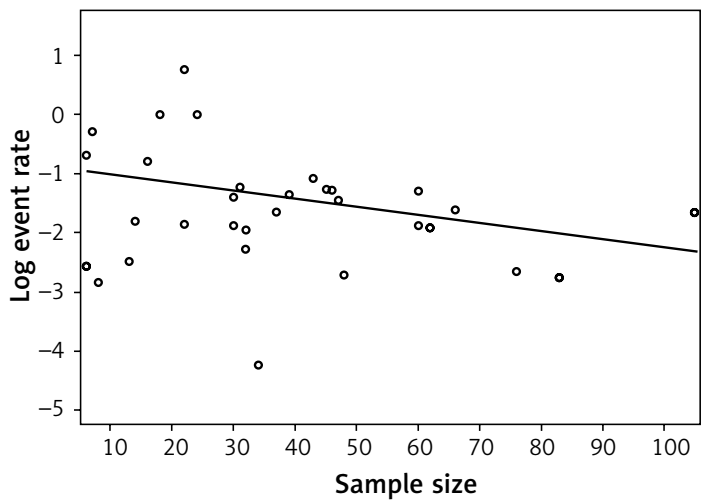

Figure 4. Meta-regression of two procedures: relation between (log cure, complications, and recurrences) and sample sizes (A, C, E) for PAIR procedures (B, D), and Lap procedures

The meta-analysis random effect model demonstrates that the complications of PAIR procedures are lower than those of laparoscopic procedures (18.5\% vs. $18.7 \%)$.

\section{Mortality}

Figures $2 \mathrm{E}$ and $\mathrm{F}$ display forest plots of mortalities using the two procedures. The results of random effect meta-analysis of mortality in PAIR and laparoscopy procedures are as follows: 
Table III. Egger's tests of outcomes PAIR and laparoscopy procedures in the treatment of liver hydatid cysts

\begin{tabular}{|lccccccccc|}
\hline Outcomes & $\begin{array}{c}\text { Interven- } \\
\text { tion }\end{array}$ & Intercept & SE & LL & UL & $t$-value & $\mathrm{d} f$ & $\begin{array}{c}\boldsymbol{P} \text {-value } \\
\text { Publication } \\
\text { bias }\end{array}$ \\
\hline \multirow{2}{*}{ Cure rate } & PAIR & 0.9501 & 0.7918 & -0.6965 & 2.5967 & 1.19999 & 21 & 0.2435 & - \\
\cline { 2 - 9 } & Lap & 2.2157 & 0.6084 & 0.9763 & 3.4550 & 3.6416 & 32 & 0.00095 & + \\
\hline \multirow{2}{*}{ Romplication } & PAIR & 0.5206 & 1.3251 & -2.2351 & 3.2763 & 0.3928 & 21 & 0.6984 & - \\
\cline { 2 - 9 } & Lap & -0.8262 & 0.730 & -2.3133 & 0.6609 & 1.1317 & 32 & 0.2662 & - \\
\hline \multirow{2}{*}{ Mortality } & PAIR & -1.0991 & 0.708 & -2.5715 & 0.3734 & 1.5523 & 21 & 0.1355 & - \\
& Lap & -0.5373 & 0.5602 & -1.6784 & 0.6037 & 0.9591 & 32 & 0.3446 & - \\
\cline { 2 - 9 } & PAIR & 1.0128 & 1.0827 & -1.2388 & 3.2643 & 0.9354 & 21 & 0.3602 & - \\
\hline
\end{tabular}

- Random effect meta-analysis of PAIR procedure: event rate $=0.011,95 \% \mathrm{Cl}$ lower limit $=$ 0.007, upper limit $=0.02, Z=-15.935, p<1 \mathrm{e}^{-16}$.

- Random effect meta-analysis of laparoscopy: event rate $=0.018,95 \% \mathrm{Cl}$ lower limit $=0.011$, upper limit $=0.029, Z=-16.231, p<1 \mathrm{e}^{-16}$.

The heterogeneity test result of the PAIR procedure is $Q=10.542, \mathrm{~d} f=22, p=0.981,{ }^{2}=0 \%$, $\Gamma^{2}=0 \%$, and the $p$-value of the heterogeneity test is not significant. This shows that the studies do not have the property of heterogeneity but it cannot be considered as homogeneous, and meta-regression is not needed. The heterogeneity test result of laparoscopy mortality is $Q=10.87$, $\mathrm{d} f=33, p=1,1^{2}=0 \%, \Gamma^{2}=0 \%$. This also shows that it does not have the property of heterogeneity but it cannot be considered as homogeneous and meta-regression is not needed.

The funnel plots of the two procedures are shown in Figures $5 \mathrm{E}$ and $\mathrm{F}$. The result of the meta-analysis for publishing bias, including Egger's regression test with intercept $=1.013$ and $p=0.36$ in the PAIR procedure, indicates no proof of publication bias, while the results of Egger's tests with intercept $=47.433$ and $p<1 \mathrm{e}^{-16}$ show publication bias in laparoscopic procedure (Table III).

The random effect meta-analysis shows that the mortality rate result of PAIR is lower than that of the laparoscopy procedure (1.1\% vs. $1.8 \%)$.

\section{Recurrence}

Figures $2 \mathrm{G}$ and $\mathrm{H}$ display forest plots of recurrences of these two procedures. Results of random effect meta-analysis of recurrence in PAIR and laparoscopy approaches are as follows:

Random effect meta-analysis of PAIR procedure: event rate $=0.05,95 \% \mathrm{Cl}$ lower limit $=0.03$, upper limit $=0.082, Z=-10.928, p<1 \mathrm{e}^{-16}$. Random effect meta-analysis of laparoscopy: event rate $=0.039,95 \% \mathrm{Cl}$ lower limit $=0.027$, upper limit $=0.058, Z=-15.508, p<1 \mathrm{e}^{-16}$.

The heterogeneity test result of the PAIR procedure is $Q=67.982, \mathrm{~d} f=22, p=1.367 \mathrm{e}^{-6}, l^{2}=$
67.639, $\Gamma^{2}=0.885$ and it is clear that the $p$-value of the heterogeneity test is significant, so the studies are heterogeneous. The heterogeneity test result of laparoscopy recurrence is $Q=41.805$, $\mathrm{d} f=33, p=0.14, l^{2}=21.062, \Gamma^{2}=0.281$. This shows that it did not have the property of heterogeneity but it cannot be considered as homogeneous.

Results of meta-regression based on published year of the PAIR procedure using the random effect model: slope $=-0.02780, \mathrm{SE}=0.05298$, $p=0.59982, \Gamma^{2}=0.9327$ (Figure $3 \mathrm{E}$ ). The $p$-value is not significant, so there is no relationship between published year and recurrence rate. Meta-regression based on sample sizes of PAIR procedure using random effect model: slope $=$ $-0.00486, \mathrm{SE}=0.00261, p=0.06278, \Gamma^{2}=0.6938$ (Figure $4 \mathrm{E}$ ). The $p$-value is not significant, so there is no relation between sample size and recurrence rate.

The published year and sample size meta-regression of PAIR studies cannot explain the heterogeneity.

The funnel plots of the two procedures are shown in Figures $5 \mathrm{G}$ and $\mathrm{H}$. The result of the meta-analysis for publication bias, including Egger's regression test with intercept $=-1.099$ and $p=0.136$ in the PAIR procedure and the results of Egger's tests with intercept $=-0.537$ and $p=0.345$ for the laparoscopic procedure indicate no proof of publication bias in either procedure (Table III).

This random effect meta-analysis shows that the recurrence rate of PAIR is higher than that of the Lap procedure (5\% vs. $3.9 \%$ ).

\section{Discussion}

In the current study, we aimed to determine the effects of PAIR and laparoscopic surgery procedures on the treatment of liver hydatid cysts. We conducted a meta-analysis of 6 prospective and 51 retrospective studies. Using overall event rate estimations demonstrated statistically significant effects of the PAIR procedure on cure rate, postop- 
A

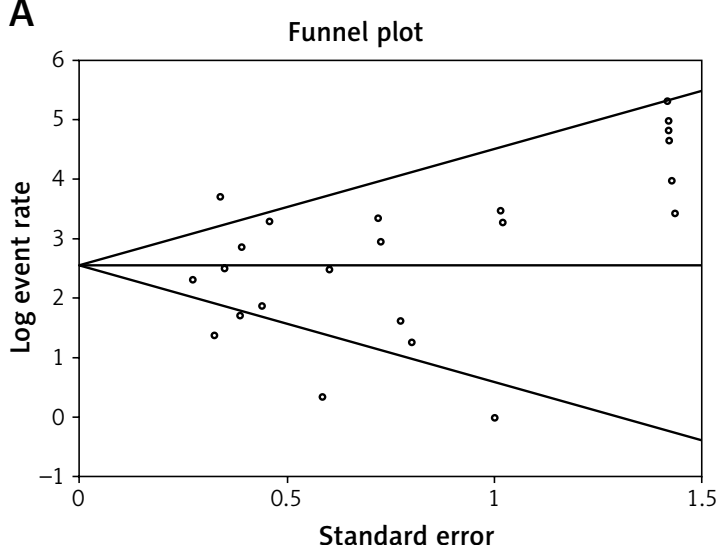

C

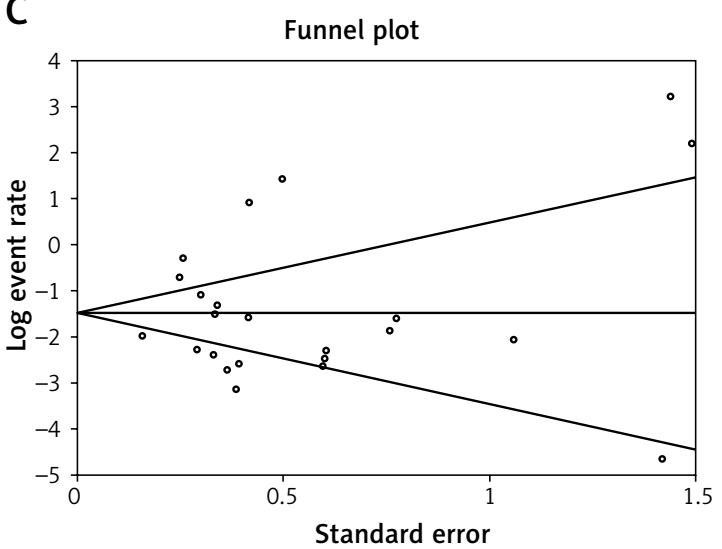

E

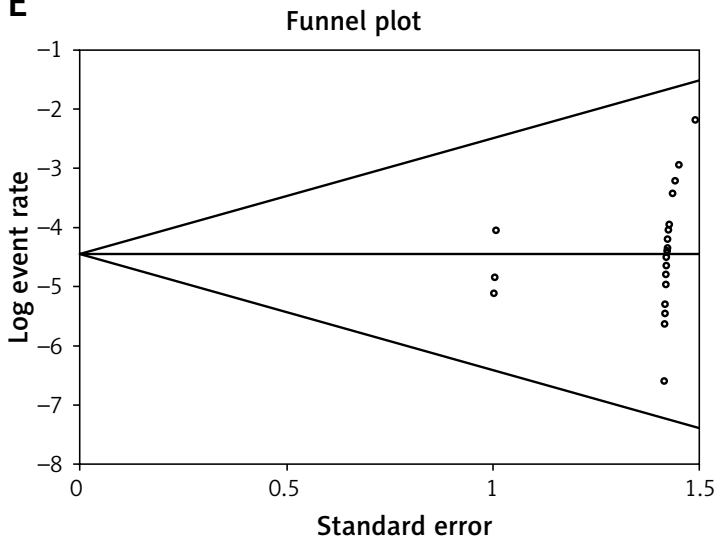

G

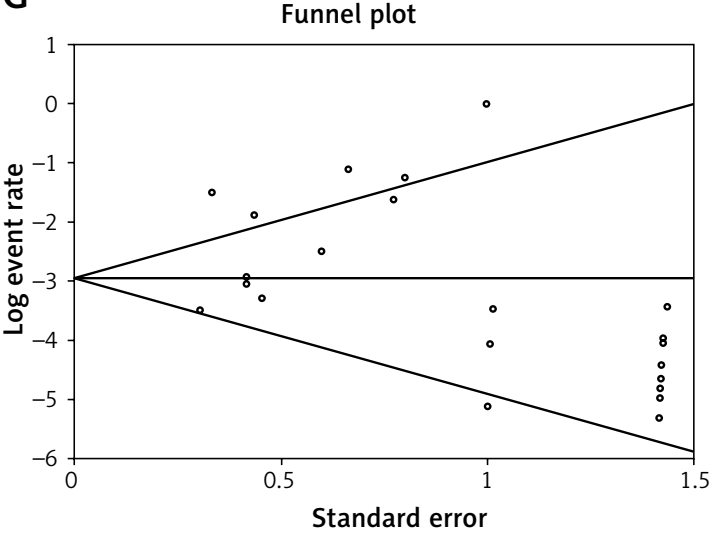

B

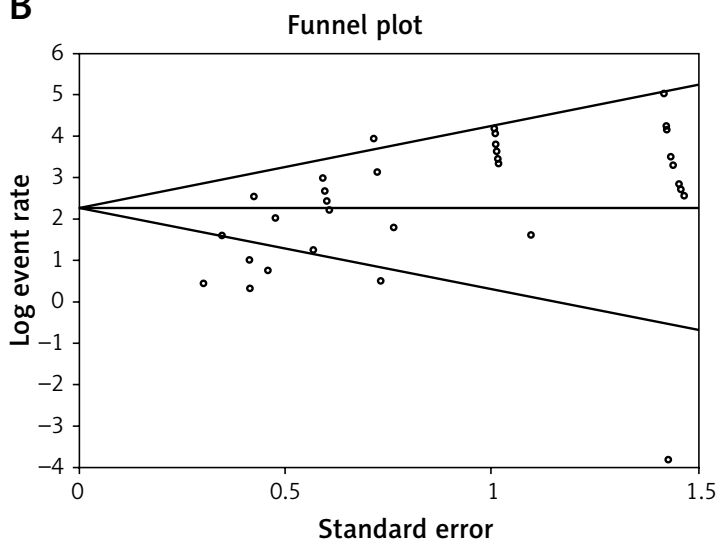

D

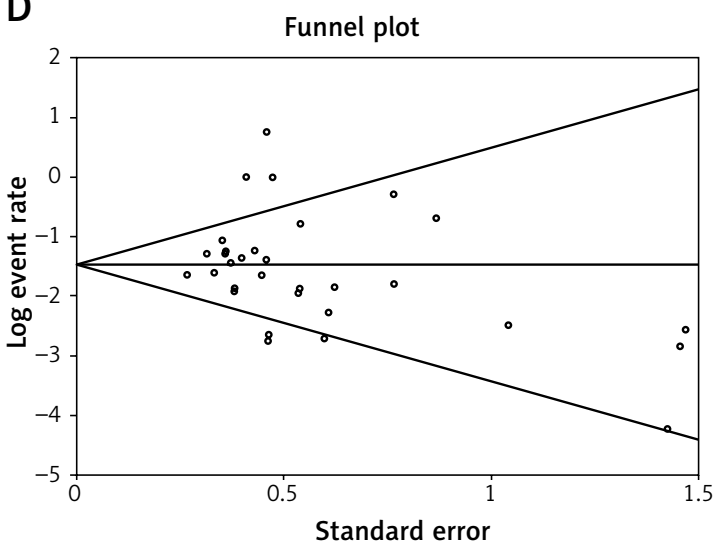

F

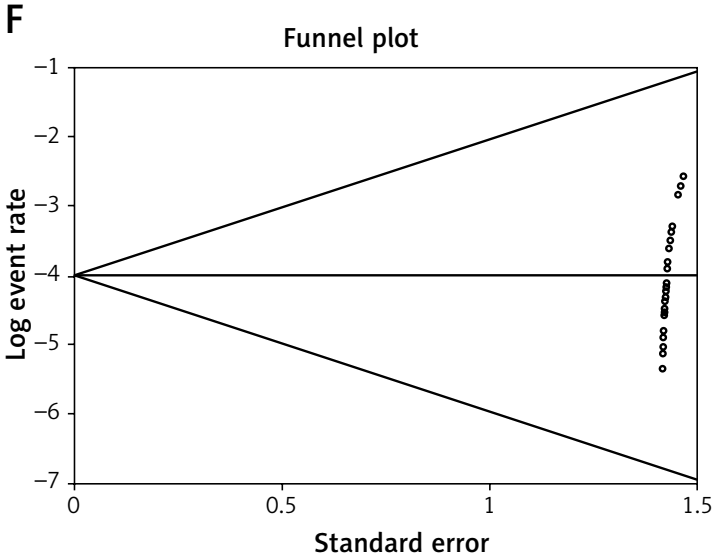

H

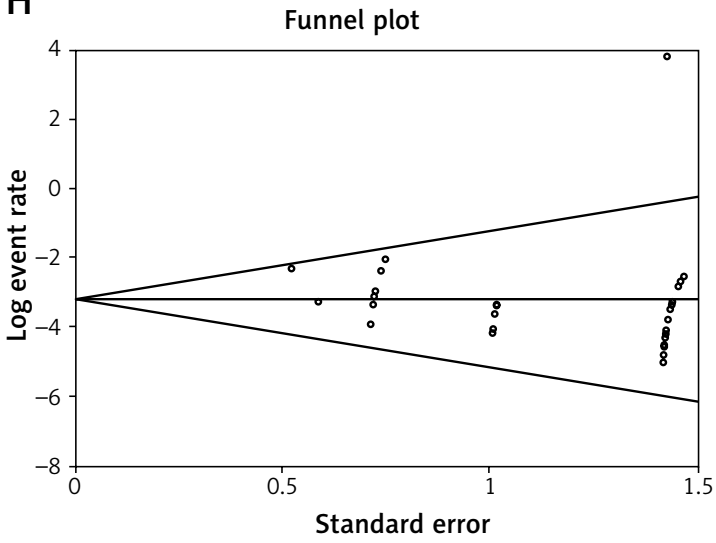

Figure 5. Funnel plots of two procedures (A, C, E, G - funnel plots of cure rates, postoperative complications, mortalities, and recurrences of PAIR group; B, D, F, H - funnel plots of cure rates, postoperative complications, mortalities, and recurrences of Lap procedure) 
erative complications, and mortality. Recurrence rates for the Lap procedure are lower than for PAIR approaches. Overall, in this study we found that the PAIR procedure is a better and preferable treatment compared to laparoscopic surgery.

There is no "best" treatment option for Echinococcus granulosus, and also there are no randomized clinical trial articles in the literature that have compared these two types of treatment modalities to date. PAIR is a minimally invasive technique and has some benefits, being less risky and more cost effective compared to laparoscopic surgery [76]. PAIR intervention has been performed under ultrasonography or tomography guidance and may not identify small or undetected cysts. The aim of PAIR therapy is to destroy the germinative layer and evacuate its contents. PAIR is not suitable for all types of hydatid cysts recommended by WHO. It is recommended in inoperable patients, or those who refuse the surgery, fail to respond to $A B Z$ alone, patients who relapsed after surgery, and in the first time treatment of stages CE1 and CE3a larger or smaller than $5 \mathrm{~cm}$ with $A B Z$ therapy. It is contraindicated in lung cysts and biliary fistula and stages CE4, CE5, CE2 and CE3b $[8,59]$.

Laparoscopic surgery for the treatment of cystic echinococcosis is a technical option in selected and uncomplicated patients, but the risk of complications, especially spillage, has never been fully evaluated [9]. Laparoscopic surgery is also a minimally invasive procedure and successful in hepatic hydatid cysts located peripherally and anteriorly. Posterior, deep cysts, and cysts located close to the inferior vena cava and calcified hydatid cysts cannot be selected for laparoscopic surgery $[9,28,54]$. Laparoscopic intervention was performed in a visual field of view under general anesthesia. Small incisions reducing post-operative pain and shortness of hospital stay are the advantages of the Lap procedure [77]. Operative laparoscopic mortality of this study is $0 \%$ while in the literature rates up to $0.22 \%$ are reported [15], and can be raised if surgical and medical facilities are inadequate [78]. The aim of this procedure is to remove cyst contents completely. The removal of the cyst is usually concurrent with partial pericystectomy. The closed type is defined as removal of the cyst content without opening the cyst and the open type as sterilizing the cyst content and scoleces with scolicidal agents and evacuating its contents [79]. Furthermore, total cystectomy may be performed by laparoscopy in advanced laparoscopic centers [53].

In this meta-analysis although the cure rate of PAIR compared with laparoscopy is higher ( $E R=$ 0.928 vs. $E R=0.907$ ), the complication rate is low $(E R=0.185$ vs. $E R=0.187)$, the mortality rate is also low $(E R=0.011$ vs. $E R=0.018)$, and it has a high recurrence rate $(E R=0.050$ vs. $E R=0.039)$. In the study of Brunetti, it has been shown that PAIR is safe and effective for many patients with cysts of stages CE1 and CE3a [8]. This meta-analysis study confirmed the WHO protocol for treatment of liver hydatid cysts at stages CE1 and CE3a but it remains debatable whether PAIR should be recommended for WHO stages CE2 and CE3b [8, 59]. Most of the reviewed studies of this article did not report based on the stages of the WHO classification.

In the comprehensive analysis study of Chen, the Lap procedure has a higher cure rate with high complication rates [1]. Inadequate response rates were not reported in our study due to insufficient data while Smego reported 2\% in the literature [76].

Indeed, PAIR was also considered a more time saving therapy than the Lap procedure.

Mean duration of hospital stay of this study in the PAIR procedure in comparison with laparoscopy is 4.2 (1-14) days vs. 5.2 (2-30) days while in the literature it is 2.2 days vs. 4.9 days. Most studies reported that the PAIR group could be discharged from hospital on the day of receiving PAIR and continue the ABZ therapy at home $[3,68]$.

In this study, the mean follow-up period of PAIR in comparison with laparoscopic procedures is 35.62 (6-720) months and 29.12 (4-132) months, respectively, which shows the high accuracy of recording of the recurrences.

These two procedures have different post-interventional complications. Anaphylactic reactions in this study occur much more frequently in patients with the PAIR intervention (3.5\%) compared with the Lap procedure $(0.17 \%)$, as confirmed by the literature [1]. After it, biliary leaks/fistula in patients with the lap procedure (1.2-4.82\%) compared with patients of the PAIR group (4.4-18\%) and the incidence of any type of infection in the Lap procedure in comparison to PAIR patients is high $(4.06 \%$ vs. $2.12 \%)$, as confirmed by the literature $[1,76]$. Failed approaches of the two abovementioned groups of this study are $0.61 \%$ in PAIR in comparison to $1.62 \%$ in the Lap procedure. It is reported as up to $23 \%$ in the Lap approach [64] and the incidence of spillage is $1.35 \%$ in the Lap and $0.1 \%$ in the PAIR procedure. This is confirmed by Smego's study [76]. Some studies have not reported the spillages of cystic content and hydatid fluid of PAIR [67, 80].

The incidences of recurrence of this study in laparoscopy and PAIR procedures are $3.64 \%$ to $3.89 \%$ (event rates: $3.9 \%$ vs. $5 \%$ ). It was reported as $0-3.3 \%$ in Lap [15] and $1.6 \%$ to $4 \%$ in PAIR approaches $[64,70,76]$.

The incidence of mortality in PAIR and laparoscopic procedures of our study are 0/1650 and $3 / 1182$ patients or $0 \%$ and $0.25 \%$ respectively 
(event rates: $1.1 \%$ vs. $1.8 \%$ ). However, these values are reported as $0.01 \%$ to $0.9 \%$ in the literature $[68,76]$.

The incidence of postoperative complications in laparoscopy and PAIR procedures was $227 / 1182$ and $300 / 1650$ patients or $19.2 \%$ vs. $18.18 \%$ (event rates: $18.7 \%$ vs. $18.5 \%$ ).

Mean hospitalization times for laparoscopic and PAIR procedures of this study were not determined due to inadequate data.

We assessed heterogeneity both graphically and quantitatively. Based on this assessment, we identified heterogeneity of the studies that may have influenced the results of our meta-analysis. In this meta-analysis, we examined cure rates, complications, mortality, and recurrences of both abovementioned procedures separately and found comparable results, which were not reported in the English language studies.

The results of the meta-analysis reported in this study should be viewed within the limitations of the included studies. Nearly all of the included studies concern selected and uncomplicated hydatid cysts of the liver. Therefore in this analysis we analyzed simple and uncomplicated forms of liver hydatid cysts. There were still several limitations: Since designing and performing prospective randomized controlled studies (RCT) studies on liver hydatid cyst treatment according to ethical issues are difficult, there were not any RCT studies in the literature to be included in our study.

Our systematic review only concerned PubMed and Scopus databases, so conference proceedings and unpublished articles were not included in our study. Hence, some valuable data may not have been considered. Any systematic review might have publication bias since it is unavoidable. In this case, we analyzed publication bias with funnel plots and Egger's regression tests.

This meta-analysis has the ability to confirm that PAIR treatment is the best approach by reducing the mortality and complication rates and achieving higher cure rates in treating uncomplicated liver hydatid cyst.

Finally, performing more RCT studies with a sufficient sample size according to ethical issues to achieve this aim is suggested for future systematic reviews and meta-analysis studies. This can improve the results of these types of studies.

In conclusion, this study is a systematic review and meta-analysis conducted on published articles of the literature that shows a significant trend toward an advantage of PAIR for treatment of liver hydatid cyst as confirmed by the WHO protocol [8]. Surgeons, advanced laparoscopists and interventional radiologists should be aware of the information and results of this study showing a higher cure rate, lower complication rate, and lower mortality in the PAIR procedure compared with laparoscopic surgery.

The only advantage and superiority of the Lap procedure is having lower recurrence in comparison to the PAIR procedure.

\section{Availability}

The stand alone meta-mums tool is available on request through the corresponding authors' e-mail addresses.

\section{Acknowledgments}

This study is part of a PhD thesis (No. 931507) and was approved and supported by Research Council of Mashhad University of Medical Sciences, Mashhad, Iran and carried out in Nuclear Medicine Research Center of Mashhad University of Medical Sciences, Mashhad, Iran.

\section{Conflict of interest}

The authors declare no conflict of interest.

\section{References}

1. Chen X, Cen C, Xie H, et al. The comparison of 2 new promising weapons for the treatment of hydatid cyst disease: PAIR and laparoscopic therapy. Surg Laparosc Endosc Percutan Tech 2015; 25: 358-62.

2. Symeonidis N, Pavlidis T, Baltatzis M, et al. Complicated liver echinococcosis: 30 years of experience from an endemic area. Scand I Surg 2013; 102: 171-7.

3. Yagci G, Ustunsoz B, Kaymakcioglu N, et al. Results of surgical, laparoscopic, and percutaneous treatment for hydatid disease of the liver: 10 years experience with 355 patients. World I Surg 2005; 29: 1670-9.

4. Akkucuk S, Aydogan A, Ugur M, et al. Comparison of surgical procedures and percutaneous drainage in the treatment of liver hydatid cysts: a retrospective study in an endemic area. Int J Clin Exp Med 2014; 7: 2280-5.

5. Polat FR. Hydatid cyst: open or laparoscopic approach? A retrospective analysis. Surg Laparosc Endosc Percutan Tech 2012; 22: 264-6.

6. Zeybek N, Dede H, Balci D, et al. Biliary fistula after treatment for hydatid disease of the liver: when to intervene. World J Gastroenterol 2013; 19: 355-61.

7. Park KH, Jung SI, Jang HC, et al. First successful puncture, aspiration, injection, and re-aspiration of hydatid cyst in the liver presenting with anaphylactic shock in Korea. Yonsei Med J 2009; 50: 717-20.

8. Brunetti E, Kern P, Vuitton D, et al. Expert consensus for the diagnosis and treatment of cystic and alveolar echinococcosis in humans. Acta Trop 2010; 114: 1-16.

9. Baskaran V, Patnaik PK. Feasibility and safety of laparoscopic management of hydatid disease of the liver. JSLS 2004; 8: 359-63.

10. Filice C, Pirola F, Brunetti E, et al. A new therapeutic approach for hydatid liver cysts. Aspiration and alcohol injection under sonographic guidance. Gastroenterology 1990; 98: 1366-8.

11. Nasseri Moghaddam S, Abrishami A, Malekzadeh R. Percutaneous needle aspiration, injection, and reaspiration with or without benzimidazole coverage for un- 
complicated hepatic hydatid cysts. Cochrane Database Syst Rev 2006; 19: 390-402.

12. Yaghan R, Heis H, Bani-Hani K, et al. Is fear of anaphylactic shock discouraging surgeons from more widely adopting percutaneous and laparoscopic techniques in the treatment of liver hydatid cyst? Am J Surg 2004; 187: 533-7.

13. Filice $C$, Brunetti E, Bruno R, et al. Percutaneous drainage of echinococcal cysts (PAIR - puncture, aspiration, injection, reaspiration): results of a worldwide survey for assessment of its safety and efficacy. Gut 2000; 47: 156-7.

14. Soper NJ, Swanström LL, Eubanks WS. Mastery of Endoscopic and Laparoscopic Surgery. $2^{\text {nd }}$ ed. Lippincott Williams \& Wilkins, Philadelphia 2004.

15. Tuxun T, Aji T, Tai Q, et al. Conventional versus laparoscopic surgery for hepatic hydatidosis: a 6-year single-center experience. J Gastrointest Surg 2014; 18: 1155-60.

16. Mozaffari S, Nikfar S, Abdollahi M. Efficacy and tolerability of renzapride in irritable bowel syndrome: a metaanalysis of randomized, controlled clinical trials including 2528 patients. Arch Med Sci 2014; 10: 10-8.

17. Qi X, Xu M, Yang $\mathrm{H}$, et al. Comparing mortality and myocardial infarction between coronary artery bypass grafting and drug-eluting stenting in patients with diabetes mellitus and multivessel coronary artery disease: a meta-analysis. Arch Med Sci 2014; 10: 411-8.

18. Zhu J, Su X, Li G, et al. The incidence of acute myocardial infarction in relation to overweight and obesity: a meta-analysis. Arch Med Sci 2014; 10: 855-62.

19. Wei C, Wen-En L, Yang-Ming L, et al. Diagnostic accuracy of loop-mediated isothermal amplification in detection of Clostridium difficile in stool samples: a metaanalysis. Arch Med Sci 2015; 11: 927-36.

20. Zhang $\mathrm{H}$, Zhang Q. Clinical efficacy and safety of colistin treatment in patients with pulmonary infection caused by Pseudomonas aeruginosa or Acinetobacter baumannii: a meta-analysis. Arch Med Sci 2015; 11: 34-42.

21. Liberati A, Altman DG, Tetzlaff J, et al. The PRISMA statement for reporting systematic reviews and metaanalyses of studies that evaluate healthcare interventions: explanation and elaboration. BMJ 2009; 339.

22. Golemanov B, Grigorov N, Mitova R, et al. Efficacy and safety of PAIR for cystic echinococcosis: experience on a large series of patients from Bulgaria. Am J Trop Med Hyg 2011; 84: 48-51.

23. Smith J. Comperehensive Meta-Analysis (Version 2) Computer software. Englewood, NJ: Biostat. Available at: https://www.meta-analysis.com/.

24. Ali FM. Laparoscopic versus open management of hydatid cyst of liver. World J Lapar Surg 2011; 4: 7-11.

25. Hrubnyk VV, Chetverikov SH, Sabri AK. The use of laparoscopic technique in the treatment of hepatic echinococcosis. Klin Khir 2001; 7: 19-21.

26. Busić Z, Cupurdija K, Servis D, et al. Surgical treatment of liver echinococcosis - open or laparoscopic surgery? Coll Antropol 2012; 36: 1363-6.

27. Busić Z, Lemac D, Stipancić I, et al. Surgical treatment of liver echinococcosis - the role of laparoscopy. Acta Chir Belg 2006; 106: 688-91.

28. Seven R, Berber E, Mercan S, et al. Laparoscopic treatment of hepatic hydatid cysts. Surgery 2000; 128: 36-40.

29. Khoury G, Abiad F, Geagea T, et al. Laparoscopic treatment of hydatid cysts of the liver and spleen. Surg Endosc 2000; 14: 243-5.

30. Pinto GP, Vallejos OC, Cruces SE, et al. Laparoscopic treatment of liver hydatid cysts. Rev Chil Cir 2011; 63: 361-7.
31. Pandey A, Chandra A, Masood S. Abdominal echinococcosis: outcomes of conservative surgery. Trans R Soc Trop Med Hyg 2014; 108: 264-8.

32. Ramachandran CS, Goel D, Arora V. Laparoscopic surgery in hepatic hydatid cysts: a technical improvement. Surg Laparosc Endosc Percutan Tech 2001; 11: 14-8.

33. Chen W, Xusheng L. Laparoscopic surgical techniques in patients with hepatic hydatid cyst. Am J Surg 2007; 194: 243-7.

34. Lv H, Jiang Y, Peng X, et al. Echinococcus of the liver treated with laparoscopic subadventitial pericystectomy. Surg Laparosc Endosc Percutan Tech 2013; 23: e49-53.

35. Palanivelu C, Jani K, Malladi V, et al. Laparoscopic management of hepatic hydatid disease. JSLS 2006; 10: 56-62.

36. Altinli E, Saribeyoglu K, Pekmezci S, et al. An effective omentoplasty technique in laparoscopic surgery for hydatid disease of the liver. JSLS 2002; 6: 323-6.

37. Manterola C, Fernández O, Muñoz S, et al. Laparoscopic pericystectomy for liver hydatid cysts. Surg Endosc Other Interv Tech 2002; 16: 521-4.

38. Ertem M, Karahasanoglu T, Yavuz N, et al. Laparoscopically treated liver hydatid cysts. Arch Surg 2002; 137: 1170-3.

39. Maazoun K, Mekki M, Chioukh F, et al. Laparoscopic treatment of hydatid cyst of the liver in children. A report on 34 cases. J Pediatr Surg 2007; 42: 1683-6.

40. Samala DS, Gedam MC, Gajbhiye R. Laparoscopic management of hydatid cyst of liver with palanivelu hydatid system over a period of 3 years: a case series of 32 patients. Indian J Surg 2015; 77: 918-22.

41. Senthilnathan P, Inamdar S, Nalankilli V, et al. Long-term results of hepatic hydatid disease managed using palanivelu hydatid system: Indian experience in tertiary center. Surg Endosc 2014; 28: 2832-9.

42. Jani K. Spillage-free laparoscopic management of hepatic hydatid disease using the hydatid trocar canula. J Minim Access Surg 2014; 10: 113-8.

43. Ramia JM, Poves I, Castellón C, et al. Radical laparoscopic treatment for liver hydatidosis. World J Surg 2013; 37: 2387.

44. Jerraya $H$, Khalfallah M, Osman SB, et al. Predictive factors of recurrence after surgical treatment for liver hydatid cyst. Surg Endosc 2015; 29: 86-93.

45. Rooh-ul-Muqim, Kamran K, Khalil J, et al. Laparoscopic treatment of hepatic hydadid cyst. J Coll Phys Surg Pakistan 2011; 21: 468-71.

46. Li H, Shao Y, Aji T, et al. Laparoscopic approach for total cystectomy in treating hepatic cystic echinococcosis. Parasite 2014: 21-65.

47. Acarli K. Controversies in the laparoscopic treatment of hepatic hydatid disease. HPB (Oxford) 2004; 6: 213-21.

48. Georgescu SO, Dubei L, Tarcoveanu E, et al. Minimally invasive treatment of hepatic hydatid cysts. Rom J Gastroenterol 2005; 14: 249-52.

49. Secchi MA, Pettinari R, Mercapide C, et al. Surgical management of liver hydatidosis: a multicentre series of 1412 patients. Liver Int 2010; 30: 85-93.

50. Kapan M, Kapan S, Goksoy E, et al. Postoperative recurrence in hepatic hydatid disease. J Gastrointest Surg 2006; 10: 734-9.

51. Zaharie F, Bartos D, Mocan L, et al. Open or laparoscopic treatment for hydatid disease of the liver? a 10-year single-institution experience. Surg Endosc 2013; 27: 2110-6.

52. Misra MC, Khan RN, Bansal VK, et al. Laparoscopic pericystectomy for hydatid cyst of the liver. Surg Laparosc Endosc Percutan Tech 2010; 20: 24-6. 
53. Tai QW, Tuxun T, Zhang JH, et al. The role of laparoscopy in the management of liver hydatid cyst: a single-center experience and world review of the literature. Surg Laparosc Endosc Percutan Tech 2013; 23: 171-5.

54. Gupta N, Javed A, Puri S, et al. Hepatic hydatid: PAIR, drain or resect? J Gastrointest Surg 2011; 15: 1829-36.

55. Odev K, Paksoy Y, Arslan A, et al. Sonographically guided percutaneous treatment of hepatic hydatid cysts: long-term results. J Clin Ultrasound 2000; 28: 469-78.

56. Bosanac ZB, Lisanin L. Percutaneous drainage of hydatid cyst in the liver as a primary treatment: review of 52 consecutive cases with long-term follow-up. Clin Radiol 2000; 55: 839-48.

57. Cakir V, Tavusbay C, Balli O, et al. Ultrasound-guided percutaneous puncture, aspiration, injection and re-aspiration (PAIR) for treatment of hepatic hydatid cysts: a preliminary report of Universal Hospital. Acta Med Mediter 2014; 30: 1361-7.

58. Polat KY, Balik AA, Oren D. Percutaneous drainage of hydatid cyst of the liver: long-term results. HPB 2002; 4: 163-6.

59. Branci S, Ewertsen C, Thybo S, et al. Cystic echinococcosis of the liver: experience from a Danish tertiary reference center (2002-2010). J Travel Med 2012; 19: 28-34.

60. Kabaalioglu A, Ceken K, Alimoglu E, et al. Percutaneous imaging-guided treatment of hydatid liver cysts: do long-term results make it a first choice? Eur J Radiol 2006; 59: 65-73.

61. Yasawy MI, Mohammed AE, Bassam S, et al. Percutaneous aspiration and drainage with adjuvant medical therapy for treatment of hepatic hydatid cysts. World J Gastroenterol 2011; 17: 646-50.

62. Akhan O, Yildiz AE, Akinci D, et al. Is the adjuvant albendazole treatment really needed with PAIR in the management of liver hydatid cysts? A prospective, randomized trial with short-term follow-up results Cardiovasc Intervent Radiol 2014; 37: 1568-74.

63. Giorgio A, de-Stefano G, Esposito V, et al. Long-term results of percutaneous treatment of hydatid liver cysts: a single center 17 years experience. Infection 2008; 36: 256-61.

64. Giorgio A, Tarantino L, de-Stefano G, et al. Hydatid liver cyst: an 11-year experience of treatment with percutaneous aspiration and ethanol injection. J Ultrasound Med 2001; 20: 729-38.

65. Wang Y, He T, Wen X, et al. Post-survey follow-up for human cystic echinococcosis in northwest China. Acta Trop 2006; 98: 43-51.

66. Gavrilin AV, Kuntsevich GI, Vishnevskiĩ VA, et al. Ultrasound-assisted puncture method of treatment of hepatic hydatid cysts. Khirurgiia 2002; 8: 39-46.

67. Aygün E, Sahin M, Ödev K, et al. The management of liver hydatid cysts by percutaneous drainage. Can I Surg 2001; 44: 203-8.

68. Köroğlu M, Erol B, Gürses C, et al. Hepatic cystic echinococcosis: percutaneous treatment as an outpatient procedure. Asian Pac J Trop Med 2014; 7: 212-5.

69. Schipper HG, Laméris JS, van-Delden OM, et al. Percutaneous evacuation (PEVAC) of multivesicular echinococcal cysts with or without cystobiliary fistulas which contain non-drainable material: first results of a modified PAIR method. Gut 2002; 50: 718-23.

70. Paksoy Y, Odev K, Sahin M, et al. Percutaneous treatment of liver hydatid cysts: comparison of direct injection of albendazole and hypertonic saline solution. Am J Roentgenol 2005; 185: 727-34.
71. Duta C, Lazar C, Bordos D. Percutaneous treatment of the liver hydatid cysts. TMJ 2004; 54: 342-5.

72. Rajesh R, Dalip DS, Anupam J, et al. Effectiveness of puncture-aspiration-injection-reaspiration in the treatment of hepatic hydatid cysts. Iran J Radiol 2013; 10: 68-73.

73. Nayman A, Guler I, Keskin S, et al. A novel modified PAIR technique using a trocar catheter for percutaneous treatment of liver hydatid cysts: a six-year experience. Diagn Interv Radiol 2016; 22: 47-51.

74. Zerem E, Jusufovic R. Percutaneous treatment of univesicular versus multivesicular hepatic hydatid cysts. Surg Endosc 2006; 20: 1543-7.

75. Grigorov N, Golemanov B, Mitova R, et al. Percutaneous puncture treatment of hepatic cystic echinococcosis under ultrasound guidance. Khirurgiia 2000; 56: 28-31.

76. Smego RAJ, Sebanego P. Treatment options for hepatic cystic echinococcosis. Int J Infect Dis 2005; 9: 69-76.

77. Goyal S, Pandit S, Raina R, et al. Our initial experience of laparoscopic management of liver hydatid disease in a Rural Medical College. Arch Clin Exp Surg 2013; 2: 16-23.

78. Junghanss T, da-Silva AM, Horton J, et al. Clinical management of cystic echinococcosis: state of the art, problems, and perspectives. Am J Trop Med Hyg 2008; 79: 301-11.

79. Xinyu P, Shijie Z, Jianhua N, et al. Total subadventitial cystectomy for the treatment of 30 patients with hepatic hydatid cyst. Chin J Gen Surg 2002; 17: 529-30.

80. vanSonnenberg E, Wroblicka JT, D'Agostino HB, et al. Symptomatic hepatic cysts: percutaneous drainage and sclerosis. Radiology 1994; 190: 387-92. 